\title{
Bimatoprost loaded nanovesicular long-acting sub-conjunctival in-situ gelling implant: In vitro and in vivo evaluation

\author{
Monika Yadav ${ }^{1}$, Ana Guzman-Aranguez ${ }^{2}$, Maria J Perez de Lara², Mandeep Singh ${ }^{1}$, \\ Joga Singh ${ }^{1}$, Indu Pal Kaur ${ }^{1} *$
}

\author{
Affiliations: ${ }^{1}$ University Institute of Pharmaceutical Sciences, Panjab University, \\ Chandigarh. \\ ${ }^{2}$ Faculty of Optics and Optometry, Department of Biochemistry and \\ Molecular Biology, Universidad Complutense de Madrid, Madrid, Spain
}

\section{Contact email: indupalkaur@yahoo.com; dripkuips@gmail.com}

\begin{abstract}
Primary treatment for glaucoma relies on chronic instillation (daily) of intraocular pressure (IOP) lowering eye drops. Present study tends to develop and assess a novel sustained release bimatoprost loaded nanovesicular (BMT-NV) - thermosensitive in-situ gelling implant (BMT-NV-GEL-IM), for subconjunctival delivery.

BMT-NVs developed using novel composition and method of preparation, (IPA/700/DEL/2014) and industrially viable methodology were characterised and evaluated comprehensively for ocular suitability. Their incorporation into an in-situ gelling formula was safe (in vitro and in vivo) and stable upon sterilization. Autoclavability was an important consideration, as a preservative-free, single-use BMT-NV-GEL-IM will avoid side- effects associated with repetitive application of drops containing preservatives like benzalkonium chloride (BAK). An extended in vitro release of BMT (80.23\%) was observed for 10 days while the IOP lowering effect extended over 2 months with single subconjunctival injection of BMT-NV-GEL-IM in rats. No clinical signs of irritation, inflammation, or infection were observed in any injected eye, throughout the study, as also confirmed by histology. Furthermore, single administration of BMT-NV-GEL as topical drop lowered the IOP over 5 days. Presence of significant diffuse fluorescence in confocal microscopy of internal eye tissues post-in vivo application, as subconjunctival implant, even after 2 month and eye drops upto1 week provide direct evidence of successful sustained delivery. We thus provide an
\end{abstract}


improved modality for antiglaucoma medication in patients who are challenged to adhere to a regimen of daily eye drops.

Keywords: Glaucoma, nanomedicine, sustained delivery, fluorescence, cytotoxicity, ocular. 


\section{INTRODUCTION}

Glaucoma comprehends a heterogenic group of ophthalmic diseases that damage the optic nerve by degenerating retinal ganglion cells (RGC), leading to progressively increasing vision loss. It is a chronic ocular disease majorly inflicting the old and requires long-term therapy sometimes extending through entire lifetime. According to World Health Organization (WHO) statistics, glaucoma is an age-related disease, which is the second leading cause of blindness in the world. Worldwide, more than 60 million individuals are afflicted by this condition, and the number is expected to increase to more than 100 million by 2040 [1]. Elevation of intraocular pressure (IOP) if corrected suitably can slow or stop the progression of the disease $[2,3]$. Both surgical and pharmacological treatment options are available. Latter involves treatment with medicated drops that reduce the production of aqueous humor (viz. $\beta$-adrenergic receptor antagonists and carbonic anhydrase inhibitors) and/or improve its outflow (viz. prostaglandins, sympatho- and parasympathomimetics, and $\alpha 2$-adrenergic receptor agonists) [4]. Prostaglandins/prostamides (PG/PM) are fast emerging, highly effective first-line therapy for glaucoma. They are able to control IOP, primarly by increasing uveoscleral outflow via remodeling of the cilliary body [5]. Out of this group, bimatoprost (BMT) a PM, is pharmacologically superior as it lowers IOP by dual pathways of increasing both the uveoscleral and the trabecular aqueous humor outflow [6] .

BMT $(0.03 \%$ solution $)$ is generally well-tolerated, cost effective [7] and thermally stable [5] amongst all prostaglandins. It is slightly soluble $(0.0187 \mathrm{mg} / \mathrm{ml})$, lipophilic ( $\log \mathrm{P}=3.2)$ molecule, with a large molecular weight (415.56Da). BMT marketed eye drop (0.03\%) effectively lower IOP, by $6.5-8.9 \mathrm{mmHg}$, over long-term use in glaucoma and ocular hypertension (OHT) [8]. A $0.03 \%$ bimatoprost, eye drops have been associated with conjunctival congestion probably due to nitric oxide-mediated vasodilatation in the conjunctiva [6], which was reduced significantly when BMT was used at a lower concentration of $0.01 \%$ (Lumigan, Allergan, Inc.). Latter formulation contains higher (4 fold) BAK concentration which is proposed to improve corneal penetration [9] and intraocular bioavailability of topically applied medications. BMT shows some adverse events iritis, hyperemia, macular edema and few cosmetic effects like (iris hyperpigmentation and eyelash growth) [6]. Howsoever to prolonged 
exposure to benzalkonium chloride (BAK) in BMT drops has shown significant toxicity against both corneal and conjunctival cells. BAK containing medications are associated with increased tearing, burning, itching, and their long-term application may result in dry eye syndrome [10]. Poor adherence to daily dosing instructions for eye drop medication is usually observed in patients suffering from chronic ocular diseases. The compliance is lowest in old patients, who have difficulty with routine daily applications. However regular application is necessary in glaucoma, permanent lowering of IOP and a failure to sick to therapy, increases risk of developing blindness $[11,12]$. Approximately half of the individuals who fill the glaucoma prescription discontinue all therapy within 6 months [13]. It was also found that $51 \%$ of patients, failed to get their prescription filled regularly in proper compliance with treatment as prescribed. Similarly $24 \%$ patients admitted to omitting eye drops either occasionally or frequently [14]. Furthermore, involuntary noncompliance is caused by the inability of the patient to place drops in the eye appropriately, leading to insufficient delivery of drug in as many as $20 \%$ of patients [15].

A favorable way of addressing poor compliance and variations/ fluctuations in IOP is the use of sustained-release systems, which maintain therapeutic drug concentrations over a prolonged time while minimizing systemic losses due to absorption through the nasal mucosa. Continuous drug release may overcome the need for daily drug administration and hence would be more economical than daily application of eye drops, since smaller amounts of drug would now achieve similar or better effect. Employing hydrogels, micelles, nanocrystals, biodegradable nanoparticles, and dendrimers have been reported to decrease the frequency of drop administration [16-18]. Similarly transitioning from ocular drops that need to be administered once a day to a drop that needs to be given once after 2-3 days could also positively impact patient adherence, but may not completely manage the issue of poor patient compliance [16].

Injections and implants release drugs within the eye and may extend the release of drug up to several weeks or months $[2,19-22]$. Biodegradable implants viz. Ozurdex ${ }^{\circledR}$ available in the market are successful, however a surgical procedure or a special device is required to implant these into the eyes [23]. In situ gelling mucoadhesive formulations are also popular. These are 
applied as simple eye drops forming a semi-solid gel as soon as they come in contact with the ocular surface. The gel should form a homogeneous layer on the corneal surface exhibiting pseudoplastic behavior during blinking to avoid patient discomfort and blurred vision while facilitating drug diffusion [24]. To be effective as a biomedical material, the transition temperature should be in the range of $10-40{ }^{\circ} \mathrm{C}$. Some liquid crystal colloidal systems are also finding use in sustained delivery of drugs [25].

To increase the convenience of administration and improve patient compliance, development of injectable drug delivery systems using conventional syringes instead of any sophisticated devices is still desired. The patient acceptance for such alternate therapies instead of eye drops was evaluated by administering a questionnaire to 151 patients with glaucoma. When questioned if they would trade their daily anti-glaucoma eye drops for a hypothetical alternate treatment mode like a 3-monthly subconjunctival injection, $74.4 \%$ patients conveyed their preference for such an injection. Subconjunctival administration is well tolerated, safe, and used routinely in clinics for the delivery of various medications [26]. Safety of subconjunctival injection of bevacizumab for dry eye disease has been reported $[27,28]$. A sustained drug release for up to 4 weeks has been shown with a subconjunctival implantation of bimatoprost (BMT) loaded natural polymer disks in rat eyes [29].

Presently, we loaded BMT in a surfactant-based novel (IPA/700/DEL/2014) nanovesicular (NV) system which was further incorporated into in-situ gelling drops or implant (GEL-IM) formula, comprising thermosensitive polymers viz. poloxamer 407 and carbopol 934P to manage any burst release of unencapsulated BMT or that present on the surface and achieve prolonged release for more than a month. The developed BMT-NV-GEL was evaluated extensively for i) particle size, zeta potential, size distribution and morphology; ii) rheology; iii) drug incorporation and compatibility with additives (DSC and FTIR); iv) stability; v) three tier: in vitro, ex-vivo and in vivo safety; vi) sustained IOP lowering effect following application as drops or as subconjunctival implant/injection and comparison of the efficacy with marketed drops of BMT in an animal model of glaucoma. 


\section{MATERIALS AND METHODS}

\subsection{Materials}

Bimatoprost (BMT) was a kind gift from FDC Ltd., Mumbai, India and poloxamer 407(P407) was gifted by Ranbaxy Pvt. Ltd., New Delhi, India. Acetonitrile (ACN) and methanol (HPLC grade) manufactured by Merck-Schuchardt, Hohenbrunn, Germany, were purchased from local vendors. HPLC grade water was produced by a Milli-DI system by Millipore (Billerica, Massachusetts, USA). Syringe filters were purchased from Waters India Pvt Ltd. All other reagents used in the study were of analytical grade.

\subsubsection{Preparation of BMT loaded nanovesicles (BMT-NVs) and gel (BMT-NV-GEL)}

\subsubsection{BM-NVS}

BMT-NVs were prepared by a modification of the ethanol-injection technique. The system was novel in terms of composition and method of preparation (IPA/700/DEL/2014). Span 60 and BMT $(0.03 \%)$ were dissolved in defined quantity of hot ethanol to form the organic phase. PEG 400 was dissolved in water and heated to $78-80^{\circ} \mathrm{C}$ (boiling point of ethanol) to form the aqueous phase. The organic phase was added in a thin but continuous stream, to the aqueous phase under continuous stirring at $1500 \mathrm{rpm}$ using a mechanical stirrer (Fig.1). The stirring was continued till volume of the mixture was reduced to the original volume of the aqueous phase, ensuring complete removal of ethanol from the final formulation. BMT-NVs were obtained as an aqueous dispersion of BMT loaded NVs and was used as such without removing unencapsulated BMT (Fig. 1). 


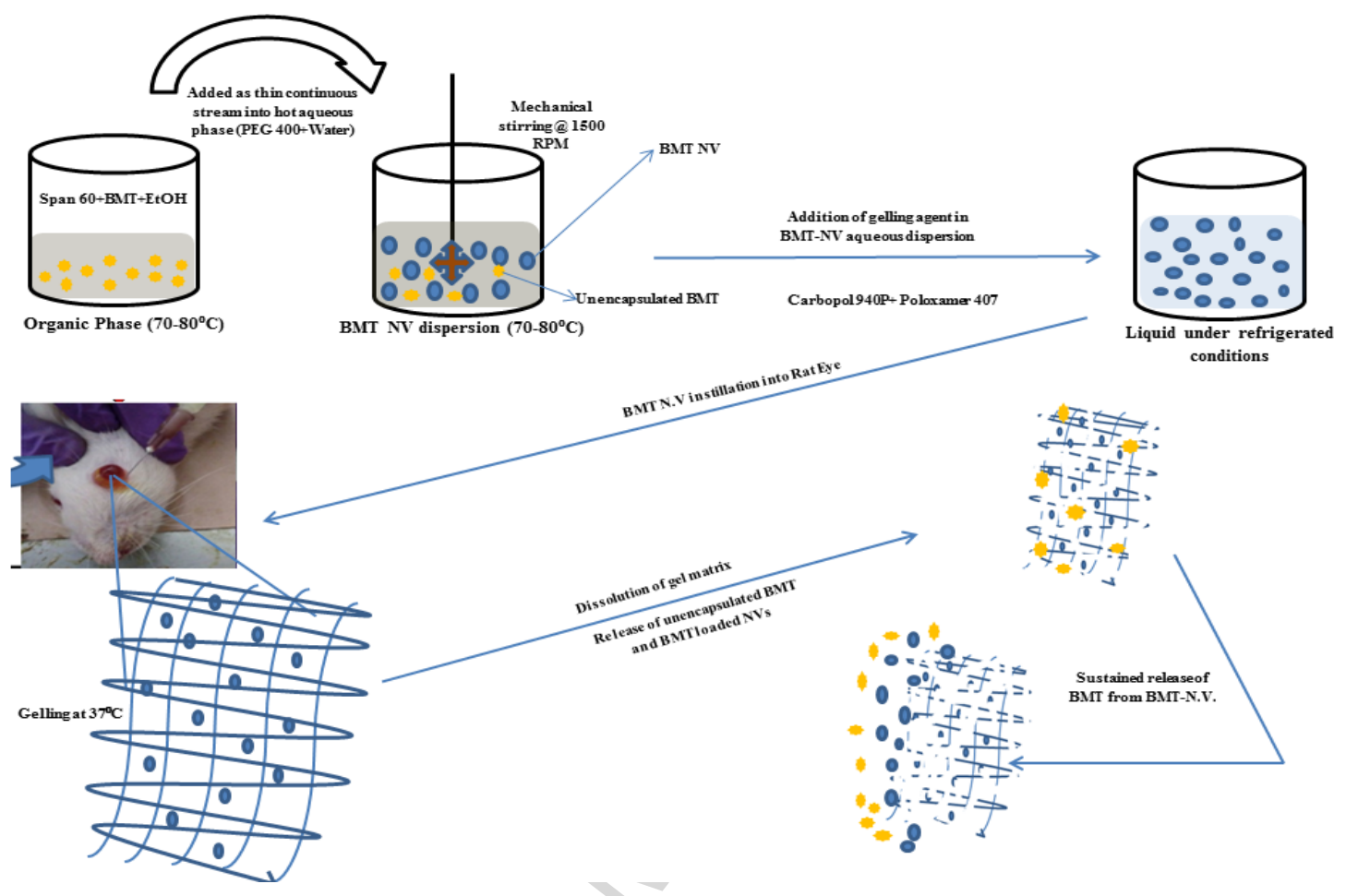

Fig. 1: Diagrammatic representation of BMT nanovesicular system fabrication, gelling on instillation into rat eye and drug release.

\subsubsection{Ethanol residue in BMT-NVs is described in supplementary data}

\subsubsection{Preparation of BMT-NV loaded gel (BMT-NV-GEL)}

BMT-NV-GEL was prepared using cold method. Required quantity of gelling polymers were added in cold water and/or in BMT-NV dispersion and kept at $4{ }^{\circ} \mathrm{C}$ with periodical stirring to ensure complete dissolution. Various combinations of viscosity enhancing polymers were tried in combination with $\mathrm{P} 407$ as described in table 1.

Note: Fluorescein sodium $(0.3 \% \mathrm{w} / \mathrm{v})$ loaded NV-GEL (F-GEL) were also prepared similarly except that BMT was replaced with fluorescein sodium.

BMT solution (BMT-SOL) 0.3\% was used as a control for BMT-NV-GEL. 


\subsection{Characterization}

BMT-NV were characterized for particle size, zeta potential, total drug content (TDC), entrapment efficiency (EE), in vitro release, transmission electron microscopy (TEM) and optical microscopy.

BMT-NV-GEL was extensively evaluated for particle size, zeta potential, TDC, DSC, FTIR, rheology, in vitro release and optical microscopy.

Details of the employed methods are elaborated below.

\subsection{Morphological analysis, size and zeta potential}

BMT-NV and BMT-NV-GEL were observed after suitable dilution (10X) with distilled water under optical microscope (Nikon eclipse i90, Japan). BMT-NVs stained using 2\% phosphotungstic acid (PTA) dissolved in $\mathrm{pH}$ 6.8, phosphate buffer, for $5 \mathrm{~min}$, were spread on a carbon coated copper grid and examined under TEM ( 80 kV, model H 100, Hitachi Ltd., Japan). Morphological parameters like size, sphericity and aggregation were noted.

\subsubsection{Particle size and zeta potential}

Mean diameter and PDI of BMT-NV dispersion and BMT-NV-GEL (10x dilution) was determined using photon correlation spectroscopy (Delsa ${ }^{\mathrm{TM}}$ Nano C, Beckman Coulter, USA). Zeta potential of the samples were measured using Delsa ${ }^{\mathrm{TM}}$ Nano C, Beckman Coulter) at $25^{\circ} \mathrm{C}$ and the electric field strength of $23.2 \mathrm{~V} / \mathrm{cm}$.

\subsubsection{Quantification of BMT (TDC and EE)}

BMT concentration in BMT-NV and BMT-NV-GEL-IM was confirmed using high performance liquid chromatography (HPLC) method. A Waters HPLC equipped with a Waters e-2695 ALLIANCE separation module comprising of 717 auto injector, a degasser module and a 2996 PDA detector was used. Waters column, Symmetry RP-18 (4.6 mm x $250 \mathrm{~mm})$ with a particle size of $5 \mathrm{~mm}$, was used for the stationary phase at room temperature. Data acquisition was performed by the Empower $2^{\circledR}$ software and the detection of BMT was carried out at $K_{\max }$ of 210 $\mathrm{nm}$. Mobile phase comprised of a mixture of $10 \mathrm{mM}$ ammonium acetate buffer: acetonitrile (45: 55 ) at a flow rate of $1.0 \mathrm{~mL} / \mathrm{min}$ with injection volume $10 \mu \mathrm{l}$. Before analysis, mobile phase was filtered through $0.2 \mu \mathrm{m}$ nylon membrane filter and degassed using sonication. All analytical 
samples were also filtered through $0.2 \mu \mathrm{m}$ nylon membrane filters before injecting into the column. Analysis was performed at column temperature of $30^{\circ} \mathrm{C}$ while the samples were maintained at a temperature of $25^{\circ} \mathrm{C}$. Samples were dissolved in isopropyl:ethanol (50:50) and all solvents used were of HPLC grade (Merck-Schuchardt, Hohenbrunn, Germany). The method was validated for accuracy, precision, LOD and LOQ in accordance with ICH guidelines. Limit of detection (LOD) and quantification (LOQ) were determined at signal to noise ratio of 3:1 and 10:1 respectively.

BMT-NV and BMT-NV-GEL dispersions $(0.5 \mathrm{ml})$ were disrupted using an appropriate quantity of a mixture of isopropyl alcohol: water (1:1) till a clear solution was obtained and the solution was filtered $(0.45 \mu)$ and suitably analyzed for BMT content using previously described and validated HPLC method.

The EE was determined by dialyzing BMT-NV dispersion $(0.5 \mathrm{ml})$ in a dialysis bag (7k Da MW cut off) immersed in $75 \mathrm{ml}$ water and stirred magnetically. After $60 \mathrm{~min}$ formulation was removed from the bag, disrupted with suitable quantity of isopropyl alcohol:water (1:1) and amount of drug was determined spectrophotometrically using HPLC. Mass balance was confirmed by measuring the quantity of BMT in the dialysate.

Both TDC and EE was determined for six different batches prepared separately to confirm reproducibility of the developed method.

\subsection{DSC and FTIR}

Samples (2-5 mg) of pure drug (BMT); various components viz. span 60, PEG 400, P407, carbopol 934P and BMT-NV-GEL and corresponding blank gel were scanned using DSC (821e Mettler Toledo, Switzerland). Thermograms were observed for shifts in peaks and/or disappearance/appearance of new peaks. Indium (m.p. $156.6^{\circ} \mathrm{C}$ and $\mathrm{H}$ of $25.45 \mathrm{~J} \mathrm{gm}^{-1}$ ) was used for calibrating the DSC for temperature and heat flow accuracy. The DSC was run from 0 to 300 ${ }^{\circ} \mathrm{C}$ at a rate of $10^{\circ} \mathrm{C} / \mathrm{min}$. Nitrogen gas was used at a purging rate of $50 \mathrm{ml} / \mathrm{min}$.

Similarly FT-IR spectra of all the above samples were also obtained over a range of 400- 4000 $\mathrm{cm}^{-1}$, using FT-IR spectrometer (Agilent Technologies 630 Cary) and Micro Lab software. 


\subsection{Determination of sol-gel transition temperature}

The sol-gel transition of combination of P407 with various viscolysing polymers was determined by inverting the test tube at $180^{\circ}$ at increasing temperatures of $1^{\circ} \mathrm{C}$ step size [30]. The vials with $0.5 \mathrm{ml}$ formulation were immersed for $1 \mathrm{~min}$, in a water bath at each temperature, and observations were made. Temperature, at which there was no visible flow within 30s of inversion, was the sol-gel transition temperature.

\subsection{Rheology is described in supplementary data}

\subsection{In vitro release}

In vitro release of drug from $0.5 \mathrm{ml}$ BMT-NV and BMT-NV-GEL were performed across the presoaked (for $12 \mathrm{~h}$ in deionized water) dialysis membrane (cut off $7 \mathrm{kDa} \mathrm{MW}$ ) mounted between the donor and the acceptor compartments of a modified Franz diffusion cell. Simulated tear fluid of $\mathrm{pH} 7.2$ was used as the receptor fluid $(20 \pm 2 \mathrm{ml})$, maintained at $37 \pm 0.5^{\circ} \mathrm{C}$ and stirred at 50 rpm. The procedure was repeated for BMT-SOL at similar concentration and under similar conditions. Aliquots of the receptor medium were withdrawn at suitable time intervals and were replaced with an equal volume of fresh medium to maintain the sink conditions. Withdrawn samples were suitably diluted and analyzed using HPLC.

\subsection{Stability study}

BMT-NV-GEL was stored in tightly closed, screw capped vials, at $2-8{ }^{\circ} \mathrm{C}$ and at $37{ }^{\circ} \mathrm{C}$ for 6 and 3 month respectively. Samples were withdrawn periodically and analyzed for particle size, total drug content and in-situ gelling behavior.

\subsection{Sterilization and sterility testing}

BMT-NV and BMT-NV-GEL were sterilized by autoclaving at $121^{\circ} \mathrm{C}(15$ psi pressure) for 20 min. Any change in terms of TDC, particle size and \% entrapment, leakiness (in case of BMT$\mathrm{NV}$ ) was noted post sterilization. Sterility testing studies were performed in order to ensure the sterility of finished autoclaved product following direct inoculation method [31]. Sample (1 ml) was drawn aseptically from the containers and transferred to fluid thioglycollate medium (50 ml) and soybean-casein digest medium $(50 \mathrm{ml})$, respectively. The medium was incubated for 14 days at $30{ }^{\circ} \mathrm{C}-35{ }^{\circ} \mathrm{C}$ in case of fluid thioglycolate medium and $20{ }^{\circ} \mathrm{C}-25{ }^{\circ} \mathrm{C}$ in case of soybean-casein 
digest medium and was observed for growth every day. Suitable negative and positive controls (Bacillus subtilis for fluid thioglycolate and Candida albicans for soybean-casein digest medium) were included in the test to confirm sterility and growth potential of the media employed respectively.

\subsection{Establishing safety of the developed system is described in data in brief [32]}

\subsection{Pharmacodynamic evaluation}

\subsubsection{Induction of glaucoma and grouping of animals}

Male Wistar rats, not more than $250 \mathrm{~g}$, bred in the Central Animal House, Panjab University, Chandigarh, India, were used. Animals caged together in groups of seven were kept under natural light/dark cycle, were given food and water ad libitum. The experimental protocol was approved by the Institutional Animal Ethics Committee (PU/IAEC/S/16/110, dated11/7/2016), Panjab University, Chandigarh, India. The baseline IOP was measured twice daily using a caliberated Schiotz A Tonometer (Riester) for 7 days in all the rats. The animals having average IOP between 14.0-16.5 mmHg were selected for the study (Fig. 2). Animals were divided into seven groups: each consisting of six animals. Group I (Naive Control) consisted of animals receiving no treatment and served as negative control. Gp II to Gp VII animals received $0.1 \%$ dexamethasone eye drops (DEX drops) 4 times a day for up to 4 weeks [33] at the same time each day. Elevation in IOP was noticed after 8 days of dosing and more than double IOP value was observed with respect to the baseline IOP in about $80 \%$ of the treated rats at the end of third week. It is reported that the elevated IOP returns to normal within a week of discontinuing DEX administration [34]. Further, since the developed implant was expected to show its efficacy at least for 2-3 months hence it was considered important to maintain the raised IOP throughout the study period by continued administration of DEX drops. However from the fourth week onwards, the dosing was reduced to two times a day, after confirming that the elevated IOP was maintained at this dosing pattern. Hence Gp II to Gp VII animals were exposed to DEX two times a day for the remaining study period. It was confirmed that there was no significant difference in IOP of rats of various groups $(\mathrm{p}=0.05)$ at the start of treatment. Gp II served as the positive control group (receiving no treatment), Group III animals received marketed drops (Lumigan $0.03 \%$ ) daily administration, Gp IV and V (vehicle control) received subconjunctival 
injection $(100 \mu \mathrm{l})$ or a drop $(30 \mu \mathrm{l})$ of Blank- NV-GEL respectively. Gp VI (BMT-NV-GEL-IM) received subconjunctival injection (a total of $100 \mu \mathrm{l}$ ) at two different sites. Procedure for subconjunctival injection was performed under topical anesthesia (paracaine 0.5\%). GpVII received single administration of BMT-NV-GEL drop $(30 \mu \mathrm{l})$. IOP was measured at different time points viz. 2, 4, 6, 12 and $24 \mathrm{~h}$ and after that daily at the same time (to correct the diurnal variations) till the time when IOP returned to baseline. Visual inspection of all eyes for clinical signs of inflammation in the eye and at the injection site and for any evidence of infection was done prior to injections and daily thereafter for one week. We used a modified version of the Moorfields bleb grading system to objectively assess vascularity in all eyes [35].

\section{In vivo experimental design}

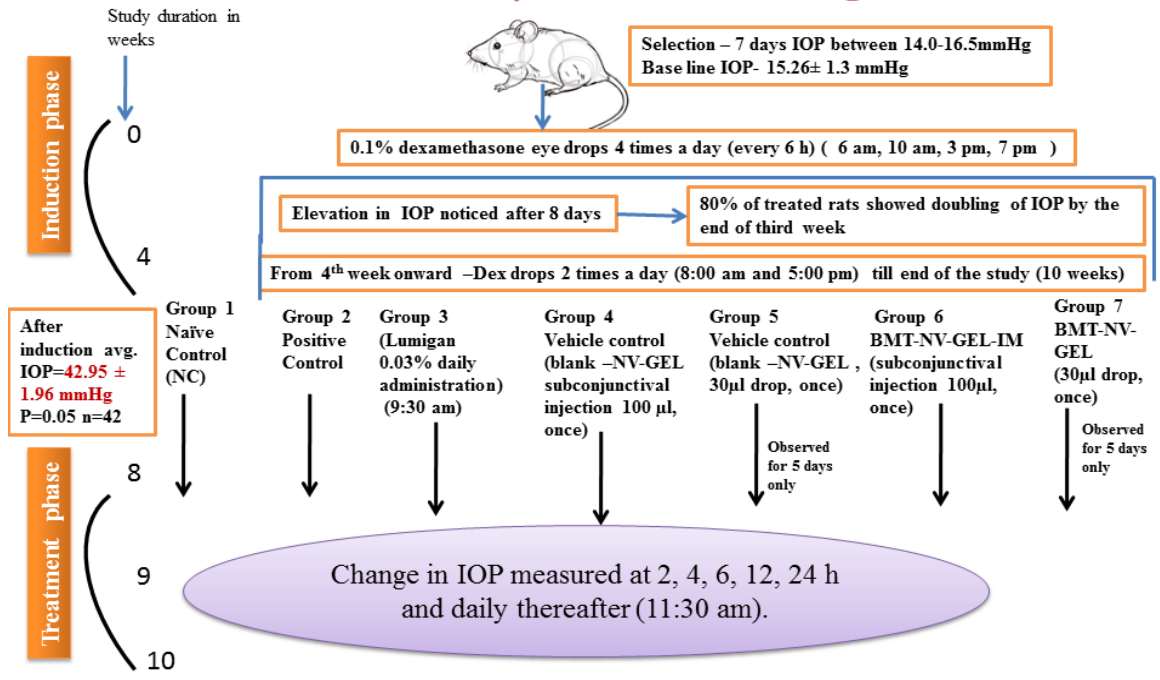

Fig.2: In vivo experiment design of pharmacodynamics study.

\subsection{Proof-of- concept studies}

\subsubsection{Cellular uptake in corneal (HCLE) and conjunctival (HCjE) cell lines}

Stratified human corneal and conjunctival epithelial cells grown on 24-well cell culture plates were incubated with F-GEL (NV-GEL loaded with fluorescein sodium $0.3 \% \mathrm{w} / \mathrm{v}$ ) or with fluorescein sodium solution $0.3 \% \mathrm{w} / \mathrm{v}$ (F-SOL), both diluted (1:20) in serum-free DMEM/F12 for $3 \mathrm{~h}$ at $37^{\circ} \mathrm{C}$. After incubation, the medium was aspirated and the cell cultures washed three times with ice-cold PBS. The cells were then solubilized in $0.1 \mathrm{M} \mathrm{NaOH} / 5 \%$ SDS, and the cell 
lysates from each well used to quantify fluorescence using a Fluoroskan Ascent FL (Thermo Fisher Scientific, Rockford, IL).

\subsubsection{Confocal microscope studies}

Fluorescein tagged BMT-NV-GEL $(100 \mu \mathrm{l})$ was injected subconjunctivaly in to the right eye of rats. Animals were sacrificed at $15^{\text {th }}$ day, 1 month and 2 month post injection of the formulation. Eyes were enucleated immediately and stored at $-20{ }^{\circ} \mathrm{C}$. The eyes were embedded in cryomatrix $^{\mathrm{TM}}$ before sectioning, and the samples were sliced into $10 \mu \mathrm{m}$ thick sections using a cryostat (IEC Minotome 3398, American Instrument Exchange, Inc., Massachusetts, USA). Sections were then fixed onto slides. The complete eye sections were observed using confocal laser scanning microscope (Nikon Eclips Ti, NIS Element, Japan) using a 63 oil immersion objective and an aperture of 1 Airy unit. All protocols were approved by the animal ethics committee (IAEC) of Panjab University, Chandigarh (PU/IAEC/S/16/110, dated11/7/2016). Stay of fluorescein tagged BMT loaded in-situ gel system was also studied when applied as ocular drops and the eyes were enucleated one week post administration.

\subsection{Statistical analysis}

All results are expressed as the mean \pm standard deviation. The results were analyzed for statistical significance by a one-way analysis of variance (ANOVA) test followed by the Tukey's test or the Students pair t test, whichever applicable. 


\section{RESULTS AND DISCUSSION}

\subsection{Preparation of BMT-NVs and BMT-NV-GEL}

Biodegradability, biocompatibility, low immunogenicity and antibacterial activity are some properties being looked into for successful use of polymers in drug delivery. A variety of foodgrade protein and polysaccharide based biopolymers, including whey proteins, casein, soy proteins, gelatin, zein, starch, cellulose, and various other hydrocolloids can be used to fabricate controlled release systems [36]. Various biopolymer drug delivery systems including hydrogels, nanoparticles, and nanogels are presently being opted as suitable carrier strategies.

Presently we employ an in situ gel-forming ophthalmic drug delivery system both as an implant and as ocular drops. Such system employs polymers that exhibit reversible phase transitions (sol-gel) and pseudoplastic behavior to (i) minimize interference with blinking and (ii) extend residence time and act as a controlled release system. Stimuli-responsive or 'smart' polymers are macromolecules that display a significant physiochemical change in response to small changes in their environment [37]. The signs or stimuli that trigger the structural changes on smart polymers can be classified in three main groups: physical (temperature, ultrasound, light or mechanical stress), chemical ( $\mathrm{pH}$ and ionic strength) and biological (enzymes and other biomolecules). Presently employed polymers were sensitive to temperature and change their microstructural features at physiological temperature. These are the most studied, used and safe polymers in drug administration systems [38].

Poloxamer (poly (ethylene oxide)-poly (propylene oxide)-poly (ethylene oxide) (PEO-PPOPEO), a thermosenstive amphiphilic block copolymer, has been explored extensively as an insitu gelling system $[39,40]$. Thermogelling of poloxamers is described by the interaction of different segments of the copolymer with each other. The poloxamer copolymers aggregate into spherical micelles, with a dehydrated core of polyoxypropylene (PPO) and the outer shell of hydrated swollen polyoxyethylene (PEO) chains [41]. With increase in temperature, dehydration and conformational changes occur at the hydrophobic chain regions, resulting to an increased chain friction and formation of a polymeric meshwork [39]. This results in availability of larger unbound water in the hydrophilic regions of the gel such that the outer PEO chains interpenetrate within the interior of the gel. The gelation is affected with the micelles remaining intact and packed orderly in a condition described in literature as the "hard-sphere crystallization" [42]. 
Though widely employed as gelling agents poloxamers are limited by their weak mechanical strength, which can result in rapid erosion [43]. Hence, we presently used a blend of poloxamer [40] and other polymers like carbopol 934 P [30, 44], HPMC [45], CMC [42], poloxamer 188 and chitosan [46] (Table 1). P407 showed a suitable in-situ gelling behavior between $37.5-39^{\circ} \mathrm{C}$ when used alone at $20 \% \mathrm{w} / \mathrm{v}$ concentration [42]. However when mixed with vesicles the gelling temperature increased to $\geq 38{ }^{\circ} \mathrm{C}$. Latter was probably due to the traces of ethanol present in the NV dispersion [39]. A blend of P407 with carbopol 934P (F12-F16; Table 1) showed a good insitu gelling behavior at $37 \pm 0.5^{\circ} \mathrm{C}$. Carbopol, a mucoadhesive polymer not only increases the mechanical strength of the formulation but also shows improved surface contact with the ocular tissues [30]. The formulation F 16 was selected as the best suitable option.

An impressive number of novel temperature-sensitive poloxamer based in situ forming system have been reported for sustained ophthalmic drug delivery but none of them can sustain the therapeutic effect of enclosed drug to more than two weeks. Thus, a combination of two drug delivery systems, i.e., NV and an in-situ gelling system (Fig. 1), were employed presently to achieve sustained therapeutic effects beyond weeks to months. Bimatoprost was incorporated into novel (IPA/700/DEL/2014) nanovesicular system which was then gelled employing an insitu gelling system.

Vesicular drug delivery systems are gaining great acceptance in drug delivery. However, these conventional systems are usually phopholipid based which although a versatile component is prone to oxidation and hydrolysis leading to compromised stability of the system [47]. The former combined with other natural ingredients, like cholesterol, of conventional vesicular systems result in decreased stability, high cost, drug leakiness and at times poor reproducibility and a batch-to-batch variation. Furthermore, the used methods of preparation like thin film evaporation, reverse phase evaporation, ethanol/ether injection and/or use of homogenisation or ultrasound technology, are suited to laboratory scale production [48]. Large scale industrial manufacturing process of uniform, reproducible, well-characterized, and stable vesicular formulation(s) essential for the commercial success of any delivery system [49] is yet to be developed. This could be the reason why these systems did not find a more wide spread applicability and market. 
In view of above, efforts of the present work were centered on devising a simple and optimized vesicular system, which is novel (IPA/700/DEL/2014) both in terms of composition and its method of preparation. The target was to define a cost effective, reproducible, and a scalable system which can effectively encapsulate the drug with minimal leakage. Synthetic components were selected, such that issues related to stability and purity of raw material with no batch to batch variation, were addressed. Another, intent of the study was to develop an effortless, simple technique of manufacture conducive to industrial scale up. The hydrophobic bilayer and small size were two other aspects focussed on.

Table 1: Optimization of BMT-NV loaded in-situ gelling system.

\begin{tabular}{|c|c|c|c|c|c|}
\hline F. Code & $\mathbf{P 4 0 7}(\%)$ & $\begin{array}{l}\text { Other } \\
\text { Polymer } \\
(\% \text { w/v })\end{array}$ & $\begin{array}{l}\text { Other Polymer } \\
(\% \text { w/v })\end{array}$ & $\begin{array}{l}\text { Vesicle+ } \\
\text { Water }\end{array}$ & In-situ gelling temp/comment \\
\hline F-1 & 26 & & - & $5+5$ & $\begin{array}{l}\text { In-situ gelling temperature was found } \\
\text { at } 28^{\circ} \mathrm{C}-30^{\circ} \mathrm{C} \text {. }\end{array}$ \\
\hline F-2 & 20 & & - & $0+10$ & $\begin{array}{l}\text { In-situ gelling temperature was found } \\
\text { between } 37.5-39^{\circ} \mathrm{C}\end{array}$ \\
\hline F-3 & 20 & & - & $5+5$ & $\begin{array}{l}\text { In-situ gelling temperature was found } \\
\text { between } 38-39.5^{\circ} \mathrm{C} \text {. } \\
\text { The increase in gelling temperature (F- } \\
\text { 2) may be due to presence of traces of } \\
\text { ethanol in vesicular system. }\end{array}$ \\
\hline F-4 & 16 & P 188 (14) & - & $5+5$ & $\begin{array}{l}\text { In-situ gelling temperature was found } \\
\text { at } 50^{\circ} \mathrm{C}\end{array}$ \\
\hline F-5 & 20 & $\begin{array}{ll}\mathrm{Na} & \mathrm{CMC} \\
\text { (3) } & \end{array}$ & - & $5+5$ & $\begin{array}{l}\text { Very thick and uneven gel was formed } \\
\text { on storage at } 4^{\circ} \mathrm{C} \text {. In-situ gelling } \\
\text { behavior was absent. }\end{array}$ \\
\hline F-6 & 20 & $\begin{array}{ll}\mathrm{Na} & \mathrm{CMC} \\
(3) & \end{array}$ & - & $5+5$ & $\begin{array}{l}\text { Uniformity and in-situ gelling behavior } \\
\text { was absent. }\end{array}$ \\
\hline F-7 & 20 & $\begin{array}{l}\text { HPMCK4 } \\
\text { M (1.5) }\end{array}$ & - & $5+5$ & Not gelled even at $50^{\circ} \mathrm{C}$. \\
\hline
\end{tabular}




\begin{tabular}{|c|c|c|c|c|c|}
\hline F-8 & 20 & $\begin{array}{l}\text { HPMCK15 } \\
(1.5)\end{array}$ & - & $0+10$ & $\begin{array}{l}\text { Found in-situ gelling behavior at } 37^{\circ} \mathrm{C} \\
\text { and very quick reversibility. }\end{array}$ \\
\hline F-9 & 20 & $\begin{array}{l}\text { HPMCK15 } \\
\mathrm{M}(1.5)\end{array}$ & - & $5+5$ & $\begin{array}{l}\text { Freely flowing at } 37^{\circ} \mathrm{C} \text { and not gelled } \\
\text { even at } 48^{\circ} \mathrm{C} \text {. }\end{array}$ \\
\hline F-10 & 16 & P 188 (14) & $\begin{array}{l}\text { Chitosan (1) } \\
\text { dissolved in in } \\
0.01 \mathrm{M} \text { glacial } \\
\text { acetic acid }\end{array}$ & $5+5$ & $\begin{array}{l}\text { Chitosan got precipitated after mixing } \\
\text { all three and storage at } 4^{\circ} \mathrm{C} \text {. }\end{array}$ \\
\hline F-11 & 16 & P 188 (14) & $\begin{array}{l}\text { Chitosan (1) } \\
\text { dissolved in in } \\
3 \% \text { citric acid }\end{array}$ & $5+5$ & $\begin{array}{l}\text { Very good sol form at } 4^{\circ} \mathrm{C} \text { but not } \\
\text { gelled even at } 45^{\circ} \mathrm{C} \text {. }\end{array}$ \\
\hline F-12 & 16 & $\begin{array}{l}\text { Carbopol } \\
934 \mathrm{P}(3)\end{array}$ & - & $5+5$ & $\begin{array}{l}\text { Showed in-situ gelling behavior at } 37- \\
38.5^{\circ} \mathrm{C} \text { but syringeability was not so } \\
\text { good. }\end{array}$ \\
\hline F-13 & 16 & $\begin{array}{l}\text { Carbopol } \\
934 \mathrm{P}(1)\end{array}$ & - & $5+5$ & $\begin{array}{l}\text { Showed in-situ gelling behavior at } 33- \\
35^{\circ} \mathrm{C} \text { and improved syringeability. }\end{array}$ \\
\hline F-14 & 14 & $\begin{array}{l}\text { Carbopol } \\
934 \mathrm{P}(1)\end{array}$ & - & & $\begin{array}{l}\text { Showed in-situ gelling behavior at } 36- \\
37^{\circ} \mathrm{C} \text { and very good syringeability. }\end{array}$ \\
\hline F-15 & 12 & $\begin{array}{l}\text { Carbopol } \\
934 \mathrm{P}(1)\end{array}$ & - & & $\begin{array}{l}\text { Showed in-situ gelling behavior at } \\
37^{\circ} \mathrm{C} \pm 0.5^{\circ} \mathrm{C} \text { and very good } \\
\text { syringeability and reversibility. }\end{array}$ \\
\hline F-16 & 12 & $\begin{array}{l}\text { Carbopol } \\
934 \mathrm{P}(1)\end{array}$ & - & $10+0$ & $\begin{array}{l}\text { Showed in-situ gelling behavior at } \\
37^{\circ} \mathrm{C} \pm 0.5^{\circ} \mathrm{C} \text { and very good } \\
\text { syringeability and reversibility. }\end{array}$ \\
\hline
\end{tabular}

\section{HPMCK15M and HPMCK4M are hydroxyl propyl methyl cellulose of grade K15M and K4M}

Several blank batches were initially prepared by varying the concentration of span 60 and PEG 400 (Table 2). Formulation F1 was selected based on smaller size, which changed minimally following sterilization by autoclaving. Since BMT is sufficiently soluble in water and highly soluble in ethanol hence it was tried to load BMT both in water as well as the organic phase.

Entrapment efficiency was remarkably high when BMT was added to the organic phase (76.4\% in comparison to $64 \%$ when loaded in aqueous phase). The unentrapped ( 24\%) BMT was not removed as its release will be sustained by the use of P407-carbopol gelling system.

Table 2: Various NV compositions used for optimization.

\begin{tabular}{|l|c|c|c|c|c|}
\hline Formulation & $\begin{array}{c}\text { Span 60 } \\
(\boldsymbol{\%})\end{array}$ & $\begin{array}{c}\text { PEG400 } \\
(\boldsymbol{\%})\end{array}$ & $\begin{array}{c}\text { TDC (EE) } \\
(\boldsymbol{\%})\end{array}$ & $\begin{array}{c}\text { Particle size } \\
(\mathbf{n m})\end{array}$ & $\begin{array}{c}\text { After autoclave } \\
\text { particle size }(\mathbf{n m})\end{array}$ \\
\hline F1 & $\mathbf{0 . 4 0}$ & $\mathbf{4 . 4 4}$ & - & $\mathbf{1 6 1 . 7}$ & $\mathbf{1 7 6 . 5}$ \\
\hline F2 & 0.80 & 11.2 & - & 182.1 & 284.3 \\
\hline F3 & 0.80 & 4.44 & - & 185.7 & 198.2 \\
\hline
\end{tabular}




\begin{tabular}{|l|l|l|l|l|l|}
\hline F4 & 0.40 & 11.2 & - & 180.5 & 198.4 \\
\hline $\begin{array}{l}\text { F1-DL } \\
\text { (organic phase) }\end{array}$ & $\mathbf{0 . 4 0}$ & $\mathbf{4 . 4 4}$ & $92.3(76.4)$ & 160.9 & 169.2 \\
\hline $\begin{array}{l}\text { F1-DL } \\
\text { (aqueous phase) }\end{array}$ & $\mathbf{0 . 4 0}$ & $\mathbf{4 . 4 4}$ & $93.2(64.0)$ & 165.2 & 177.4 \\
\hline
\end{tabular}

F1-DL (organic phase) - when drug D (bimatoprost) was incorporated in the organic phase during preparation of $\mathrm{NV}$

F1-DL (aqueous phase) - when drug D (bimatoprost) was incorporated in the aqueous phase during preparation of $\mathrm{NV}$

Results of gas chromatography of BMT-NV (Supplementary Fig. S1 and Supplementary Table S1) showed a peak corresponding to ethanol which is a class 3 solvent and is considered to be safe at or below $5000 \mathrm{ppm}(0.5 \%)$ concentration in pharmaceutical formulations as residual solvent [50]. Comparing the AUC of $5000 \mathrm{ppm}$ ethanol and the peak shown by BMT-NV corresponding to ethanol (RT 2.35 and 2.33 respectively), it can be concluded that amount of residual ethanol in the BMT-NV is sufficiently below ( $40 \%)$ the allowed limit of $5000 \mathrm{ppm}$ which will be further lowered by addition of polymers in the final BMT-NV-GEL formulation. USFDA approves the limit of ethanol in an ophthalmic solution as $1.43 \%$ [51].

\subsection{Characterization}

\subsubsection{Morphological analysis.}

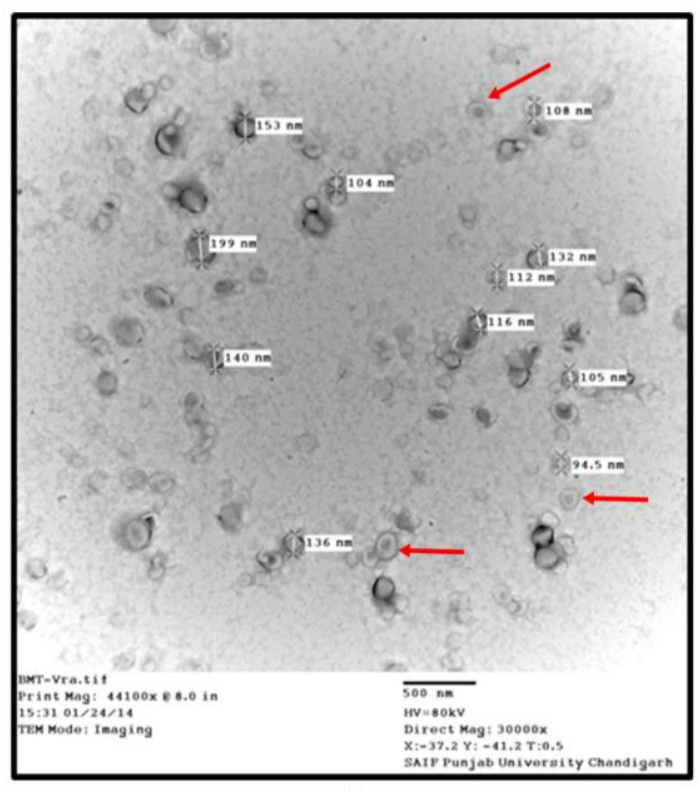

(a)

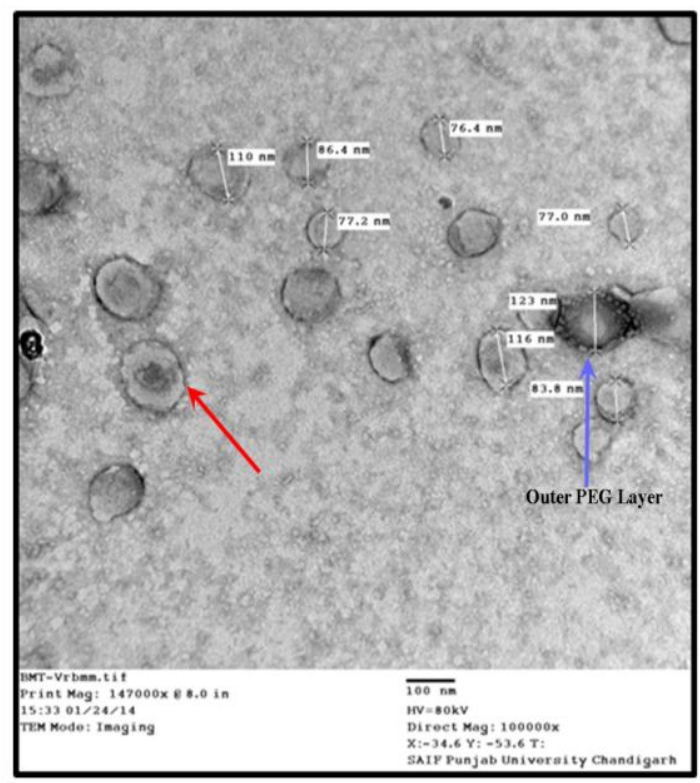

(b) 
Fig. 3: TEM micrographs of BMT-NV at a) 30000x, b) 100000x magnification Red arrows indicate bilamellar NVs

Both optical microscopic (Supplementary Fig. S2) and TEM images of the BMT-NV (Fig. 3) indicated their small size, round, unilamellar/bilamellar structure with no aggregation or irregularities. Furthermore their hollow, central core enclosed by bilamellar structure, confirmed their vesicular characteristics. A dark outer lining/surface observed around the vesicles is the PEG coating, which will assign a i) suitable rigidity to the vesicles ensuring their stability [52] even following autoclaving; and ii) $\mathrm{P}_{\mathrm{gp}}$ efflux inhibition capacity, coupled with the capacity to bypass reticulo-endothelial system (RES) pickup of the developed vesicles. Incorporation of PEG in the normal architecture of these vesicles is a better option than the PEGylated systems where PEG is attached on the surface either by surface adsorption or covalent binding [53]. Latter not only involves a separate manufacturing step but may also increase the size of resulting vesicles and can be removed on dilution.

Further, microscopic images of BMT-NV-GEL clearly indicated uniformly distributed vesicles embedded in gel network (Supplementary Fig. S3).

\subsection{Particle size and zeta potential}

The developed BMT-NV showed an average particle size $(n=6)$ of $165.7 \pm 10.5 \mathrm{~nm}$ and PDI of $0.147 \pm 0.02(\mathrm{n}=6)$. The PDI $<0.2$ indicates narrow particle size distribution. Small size offers a greater surface area for association with conjunctiva, thus resulting in higher permeation of intact vesicles [54]. Retention and ocular distribution of subconjunctivaly administered nanoparticles of varying size (20 nm and $2000 \mathrm{~nm})$ and of microparticles $(2 \mu \mathrm{m})$ [55] indicated that very small particles $(20 \mathrm{~nm})$ undergo rapid clearance from the periocular tissue as compared to the larger particles (200 nm and $2 \mu \mathrm{m}$ ) which are retained for periods as long as two months. Systemic clearance via periocular blood or lymphatic circulation was indicated as a probable reason for rapid clearance of small particles when administered subconjunctivaly [56]. However particles $\geq$ $200 \mathrm{~nm}$ could not cross the various ocular barriers, indicating particles $>20 \mathrm{~nm}$ and $<200 \mathrm{~nm}$ to be of a favorable size for greater ocular uptake. Particle size distribution of presently prepared and reported formulation (Supplementary Fig. S4a) shows that none of the particle is less than 63 $\mathrm{nm}$ or in micron size. Majority ( $80 \%$ ) of the particles were found to lie in the range of $60-257$ $\mathrm{nm}$ hence the achieved particle size is expected to show favorable periocular and subconjunctival 
retention and uptake. Furthermore incorporation of BMT-NV into an in-situ gelling system (average particle size $810 \pm 12.3 \mathrm{~nm}$ ) confirms their enhanced retention for longer time (Supplementary Fig. S4b).

Zeta potential of BMT-NV was $-46.39 \mathrm{mV}$ while that of BMT-NV-GEL was $-4.67 \mathrm{mV}$. A zeta of $\geq 25 \mathrm{mV}$ imparts stability to aggregation. Formation of binary mixture of ethanol-water (when organic and water phase are mixed) was considered responsible for the presently observed negative zeta potential [57].

\subsection{Quantification of BMT}

The calibration curve of BMT in ethanol:water (50:50) was found to be linear at the tested concentration range of 1.0 to $50.0 \mu \mathrm{g} / \mathrm{ml}$, with $\mathrm{r}^{2}$ value of 0.999 . The method was validated in terms of inter-day and intra-day variation and the \% RSD value was found to vary between 1.87 to 2.62 and 1.01 to $2.67 \%$, respectively (Supplementary Table S2) upon repetitive determinations ( $n=3$, in both case) which proves the fitness of the developed method as per ICH guideline (precision $\leq 3$ ). The limit of detection (LOD) and quantification (LOQ) determined at signal to noise ratio 3:1 (LOD) and 10:1 (LOQ) was $0.2 \mu \mathrm{g} / \mathrm{ml}$ and $0.4 \mu \mathrm{g} / \mathrm{ml}$ respectively.

Standard plot of BMT was also prepared in isopropyl alcohol: water (50:50) for determination of TDC and EE by HPLC. A linear correlation was obtained $\left(r^{2}=0.999, n=3\right)$ at the tested range (1$50 \mu \mathrm{g} / \mathrm{ml})$.

\subsection{Total drug content (TDC) and entrapment efficiency (EE)}

The drug content of the developed BMT-NV was $2.81 \pm 0.05 \mathrm{mg} / \mathrm{ml}$ which was $93.34 \pm 1.21 \%$ of what was originally incorporated $(3 \mathrm{mg} / \mathrm{ml})$ and the entrapment efficiency was $76.8 \pm 1.52 \%$ $(n=6)$. Incorporation of BMT-NV into in-situ gelling formula resulted in TDC of the final formulation (BMT-NV-GEL) of $2.70 \pm 0.04 \mathrm{mg} / \mathrm{ml}(90 \%$ of initially incorporated BMT concentration).

\subsection{DSC and FTIR}

The DSC spectra for BMT, span 60, PEG 400, P407, carbopol 934P, Blank -NV-GEL and BMTNV-GEL are shown in fig. 4a. Melting endotherm of BMT, corresponding to its melting point appeared at $71.48{ }^{\circ} \mathrm{C}$ with an enthalpy of $79.30 \mathrm{~J} / \mathrm{g}$. P407 showed a sharp peak at $57.29{ }^{\circ} \mathrm{C}$ with enthalpy $166.1 \mathrm{~J} / \mathrm{g}$ and an endotherm at $50.68^{\circ} \mathrm{C}(65.53 \mathrm{~J} / \mathrm{g})$ was observed for span 60 . Carbopol 934P showed broad endotherms at $77.42{ }^{\circ} \mathrm{C}$ and $185.11^{\circ} \mathrm{C}$ which disappeared in the blank-NV 
loaded gel and BMT-NV-GEL, indicating carbopol skelton probably intertwine P407 gelling network. A somewhat sharp endotherm corresponding to span 60 at $50.48^{\circ} \mathrm{C}$ with a significantly low enthalpy observed for blank (7.05 J/g) and BMT loaded NV-gel (41.54 J/g) indicate a stable nanosystem with efficient incorporation of BMT in to the NV. A higher enthalpy observed for BMT-NV gel $(41.54 \mathrm{~J} / \mathrm{g})$ versus blank gel $(7.05 \mathrm{~J} / \mathrm{g})$ may be attributed to incorporation of unentrapped BMT and PEG 400 into the in-situ gelling network.

The FTIR spectra for BMT, Blank -NV-GEL, BMT-NV-GEL and all other excipient are shown in fig. 4b. Free BMT showed intense absorption bands at $3311 \mathrm{~cm}^{-1}\left(\mathrm{O}-\mathrm{H}\right.$ stretch), $3430 \mathrm{~cm}^{-1}$ (N-H stretch), $3078 \mathrm{~cm}^{-1}$ (aromatic C-H stretch), $2932 \mathrm{~cm}^{-1}$ (aliphatic C-H stretch) $1641 \mathrm{~cm}^{-1}$ ( $\mathrm{C}=\mathrm{O}$ stretching of amide), $1549 \mathrm{~cm}^{-1}\left(\mathrm{C}=\mathrm{C}\right.$ aromatic stretch) and1269 $\mathrm{cm}^{-1}$ (C-N stretching of amide), respectively. $\mathrm{P} 407$ exhibit characteristic peaks at $2882 \mathrm{~cm}^{-1}$ (alkane stretch), $1357 \mathrm{~cm}^{-1}$ (In plane $\mathrm{O}-\mathrm{H}$ blend) and $1109 \mathrm{~cm}^{-1}$ representing $\mathrm{C}-\mathrm{O}$ bond stretch. Carbopol 934P showed intense absorbtion peaks at $2929 \mathrm{~cm}^{-1}\left(\mathrm{O}-\mathrm{H}\right.$ stretch) and $1714.53 \mathrm{~cm}^{-1}$ (carboxyl group stretch). Presence of characterstics peaks corresponding to P407 $\left(2880 \mathrm{~cm}^{-1}, 1354 \mathrm{~cm}^{-1}, 1109.24 \mathrm{~cm}^{-1}\right.$ and $\left.842 \mathrm{~cm}^{-1}\right)$ and carbopol $934 \mathrm{P}\left(1714.53 \mathrm{~cm}^{-1}\right.$; carboxyl group which is shifted to somewhat higher wavelength i.e $1731 \mathrm{~cm}^{-1}$ ) was observed both for Blank-NV and BMT-NV-loaded gel. This observation indicates that Carbopol 934P intertwine with P407 gel network.

The similarity of the FTIR spectra obtained for BMT-NV-GEL to that exhibited by blank-NVGEL and absence of specific peak corresponding to BMT in the former, confirms efficient encapsulation of BMT within the vesicular system. Although entrapment efficiency obtained by the analytical procedure is $76.8 \% \mathrm{w} / \mathrm{v}$, it may be said that the unentrapped free drug $(\sim 24 \%)$ is also entrapped with in the in-situ gelling network of P407 and carbopol 934P, so that it is not identifiable as a separate unit by FTIR. 


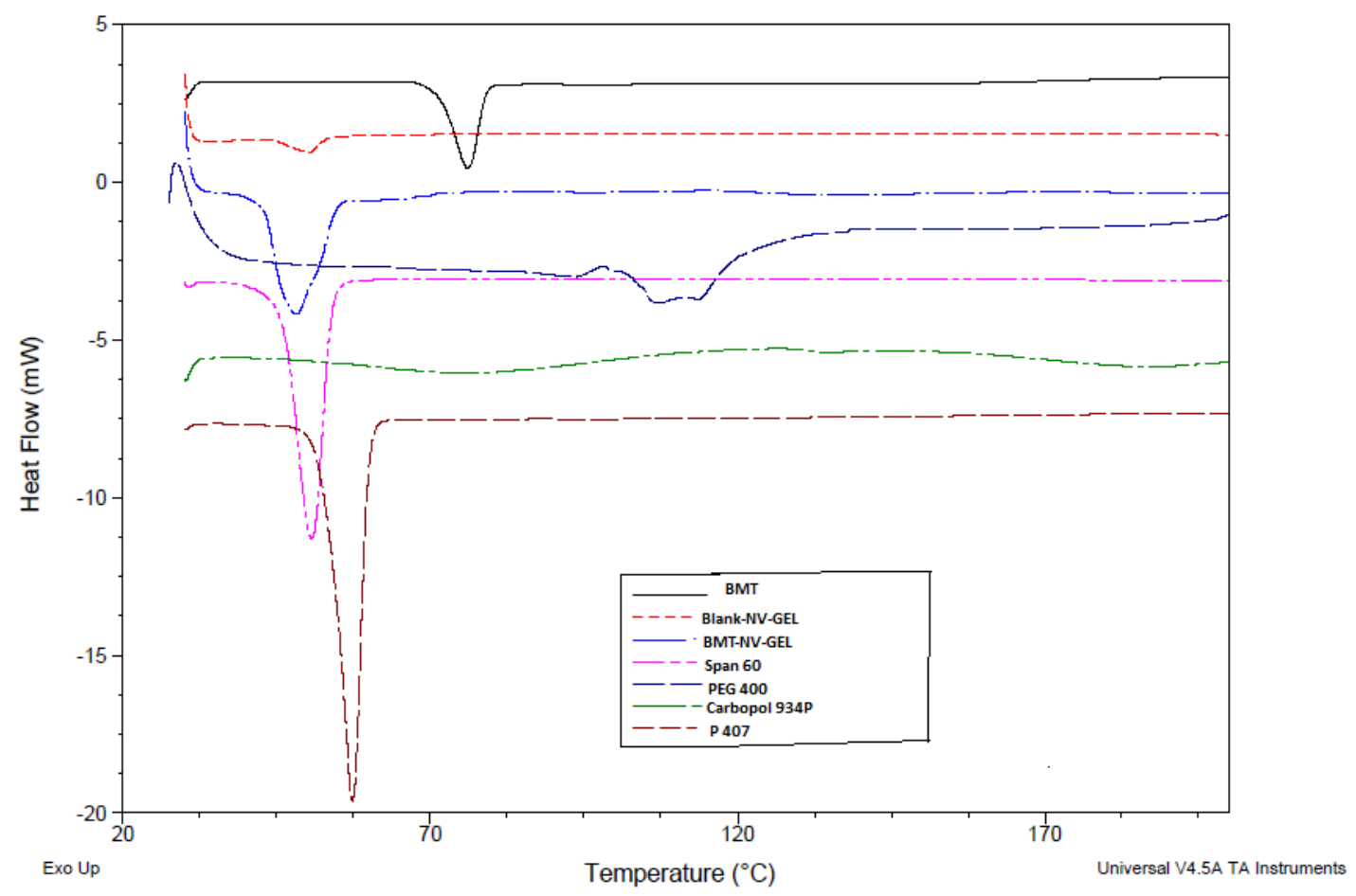

(a)
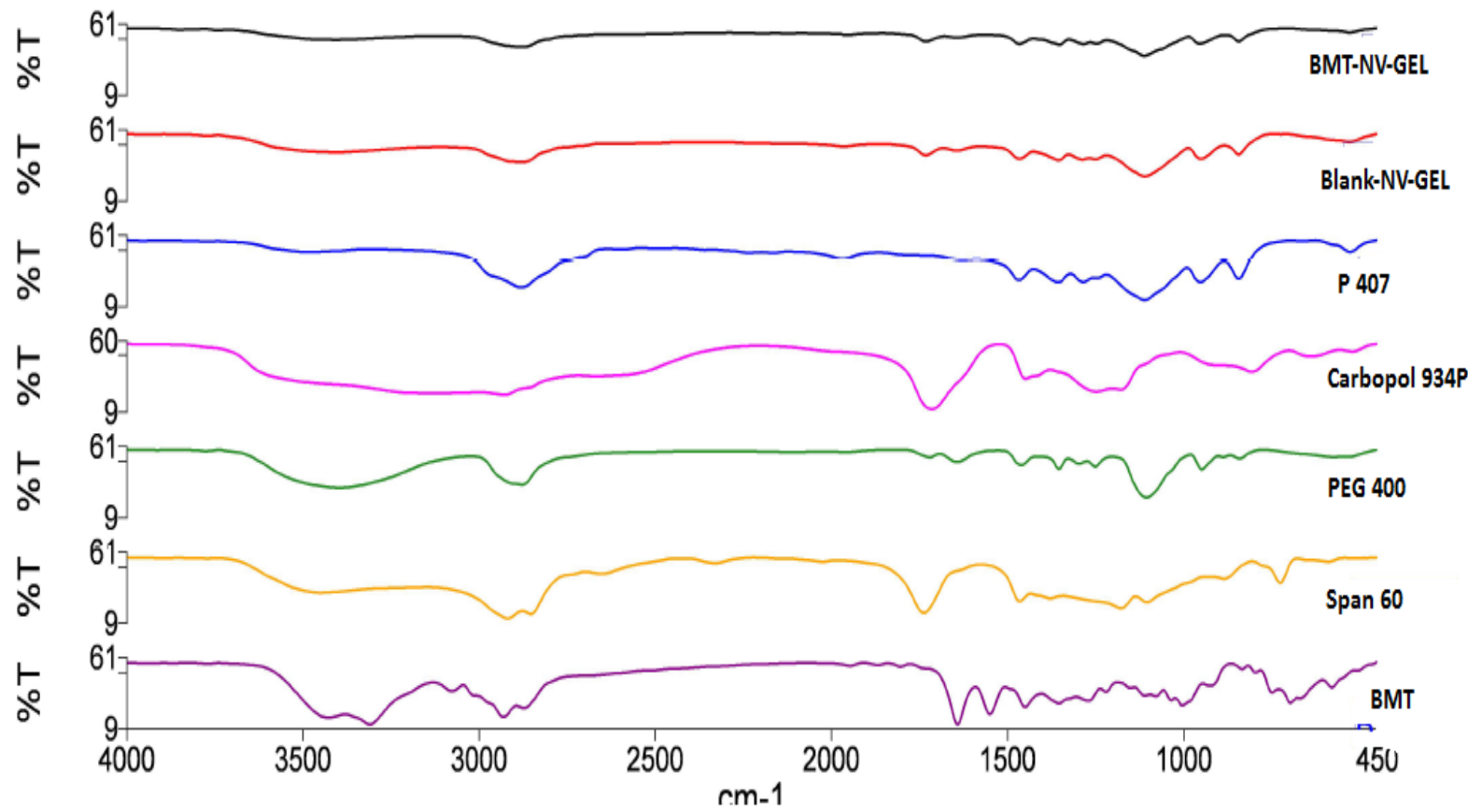

(b)

Fig. 4: DSC (a) and FTIR (b) spectra of BMT, BMT-NV-GEL, Blank-NV- GEL, and various components of BMT-NV-GEL. 


\subsection{Determination of sol-gel transition temperature}

Sol-gel transition temperature of the final formulation was found to be $37 \pm 0.5^{\circ} \mathrm{C}(\mathrm{n}=6)$. Gelation of P407 takes place due to orientation of body centered cubic packaging of its spherical micelles at above critical micellar concentration $(1 \mathrm{mg} / \mathrm{ml})$. Temperature plays important role in the micelle formation of $\mathrm{P} 407$ through the temperature dependent hydration of ethylene oxide units. At lower temperature, water serves as good solvent for PEO and PPO units of P407 such that hydrogen bonding between PPO chains and water keeps hydrophobic portions of poloxamers separate. At higher temperature, hydrogen bonding is disrupted and hydrophobic interactions causing a gel to be formed. Thus, gelling properties of poloxamers are dependent on proportion of hydrophobic portion. It is reported and was also observed presently that P407 at the concentration of $18-20 \%$ gels between $37-38^{\circ} \mathrm{C}$. Decrease in gelation temperature was observed with increase in P407 concentration due to increase in its hydrophobic portion [45]. To develop in-situ forming delivery system of BMT-NV using lower concentration of P407 (14\%), it was combined with other polymers viz. carbopol 934P, HPMC, P188 and CMC which are reported to exhibit reversible sol-gel phenomenon at lowered P407 concentration [39, 45]. Similar was observed presently on combining P407 with 1\% carbopol 934P, when the required concentration of P407 reduced from $20 \%$ to $14 \%$. Consistent properties were maintained when P407 concentration was lowered from 14 to $12 \%$. The gelation temperature of $14 \%$ aqueous solution of $\mathrm{P} 407$ alone is reported to lie between $43-45^{\circ} \mathrm{C}[46,58]$. Addition of carbopol 934P resulted in the formation of hydrogen bonding with ethereal oxygen of P407, resulting in a decreased gelation temperature. A progressive decrease in sol-gel transition temperatures with increase in carbopol 934P concentrations was observed. Similar is also reported in earlier studies [43]. Agents like ethanol, propylene glycol, and hydrochloric acid, which form weak hydrogen bonds, however tend to increase gelation temperature [39]. Similar was noted when P407 was added directly into BMT-NV probably containing traces of ethanol.

\subsection{Rheology of BMT-NV-GEL is discussed in supplementary data}

\subsection{In-vitro release}

The drug release profile of BMT-NV and BMT-NV-GEL indicates biphasic release kinetics of BMT as shown in fig. 5. BMT showed a prolonged release with 93\% drug release at $144 \mathrm{~h}(6$ days) from BMT-NV. BMT-NV-GEL showed an even better sustained effect with $51 \%$ drug release at $144 \mathrm{~h}$ and $80.23 \%$ at $240 \mathrm{~h}$ (10 days). However approximately $24 \%$ of the drug was 
released initially within $2 \mathrm{~h}$ from BMT-NV. This corresponds to the unentrapped drug ( $26.4 \%)$ concentration. The slightly soluble nature of BMT and its partial incorporation in the outer PEG layer of vesicles could also be responsible for the initial release [59]. PEG has strong affinity for water phase hence drug incorporated in outer PEG layer is expected to be released fast. The initial phase of release was however substantially diminished in BMT-NV-GEL indicating that free BMT was now entrained within the P188 and carbopol 934P gel matrix. Both BMT-NV and BMT-NV-GEL showed first order drug release $\left(r^{2}=0.972\right.$ and 0.982) for the first $2 \mathrm{~h}$, after which the release followed a zero order $\left(r^{2}=0.972\right.$ and 0.962) pattern indicating controlled release. Out of the various models, Higuchi release model $\left(r^{2}=0.986\right.$ and 0.952$)$ was best fitted for both BMTNV and BMT-NV-GEL indicating that drug release occurs by diffusion. Further fitting of the data in the Korsmeyer-Peppas equation indicate that the mechanism of drug release was Fickian, as the diffusion exponent ( $n$ value) value was $<0.45$ (0.224 and 0.293 for BMT-NV and BMT-NVGEL respectively). 


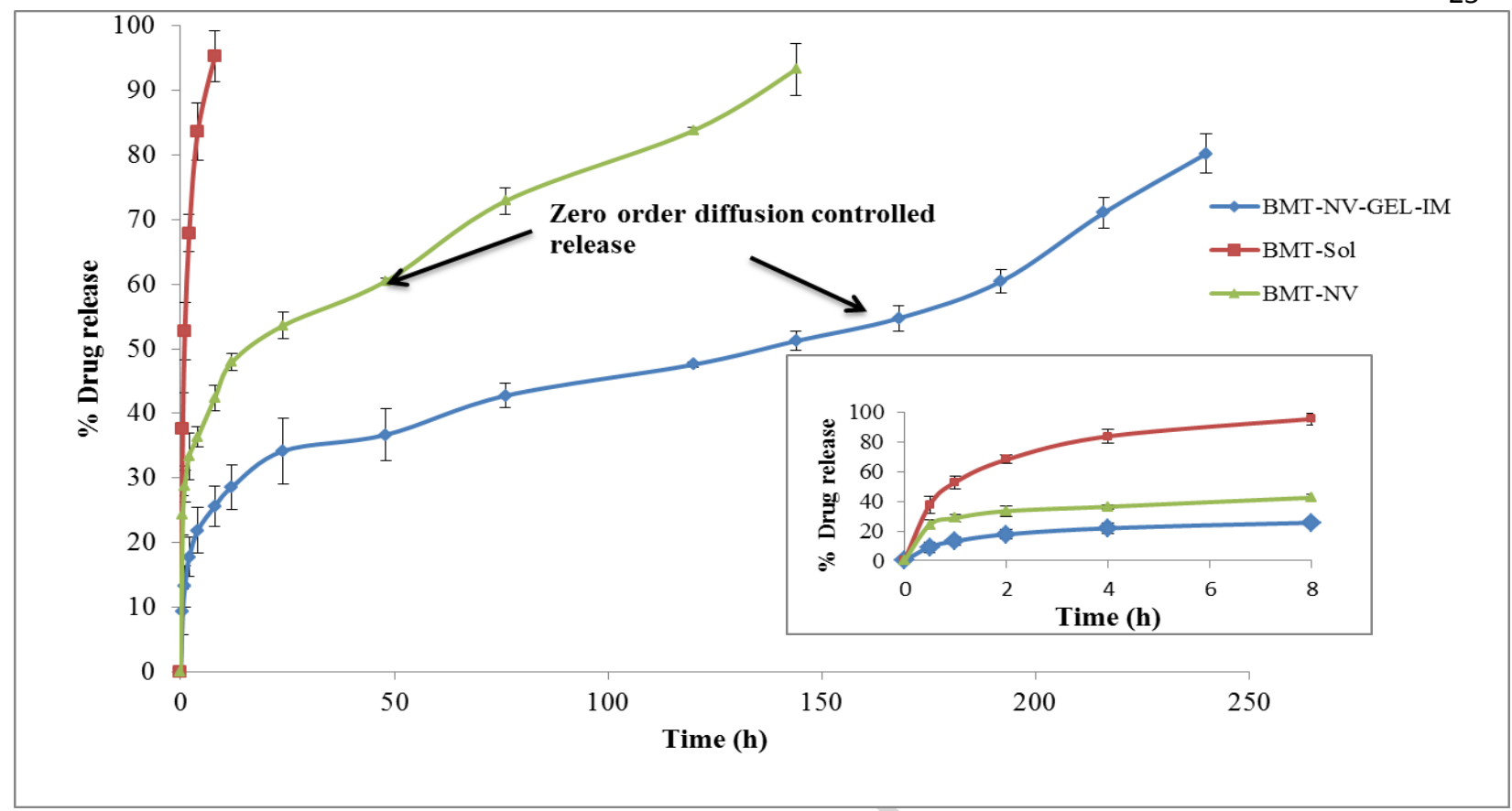

Fig. 5: In vitro drug release of BMT-SOL, BMT-NV and BMT-NV-GEL in simulated tear fluid (pH 7.2)

\subsection{Stability study}

No significant change $(\mathrm{p}<0.001)$ in TDC and particle size of BMT-NV-GEL was observed upon storage under refrigeration for 6 months and at $37 \pm 2{ }^{\circ} \mathrm{C}$ for 3 months indicating their long term stability (Table 3 and Table 4). TDC of BMT-SOL (99.7 \pm 0.52$)$ was however reduced by almost $(8 \%)$ at 6 months under refrigerated conditions.

Table 3: Stability study at $5 \pm 3^{\circ} \mathrm{C}(\mathrm{n}=3)$

\begin{tabular}{|c|c|c|c|c|}
\hline \multicolumn{5}{|c|}{ \% Change in parameters with time } \\
\hline \multirow{2}{*}{$\begin{array}{c}\text { Time } \\
(\text { months) }\end{array}$} & TDC & $\begin{array}{l}\text { In-situ gelling } \\
\text { property at 37 } \mathbf{C}\end{array}$ & Particle size & TDC \\
\cline { 2 - 5 } & $0.63 \pm 0.12$ & Maintained & $1.04 \pm 0.80$ & $1.5 \pm 0.51$ \\
\hline 1 & $1.02 \pm 0.15$ & Maintained & $1.92 \pm 1.05$ & $2.9 \pm 1.0$ \\
\hline 3 & $1.74 \pm 0.51$ & Maintained & $3.1 \pm 1.36$ & $7.6 \pm 1.6$ \\
\hline 6 & & & & \\
\hline
\end{tabular}

Values were not significantly different from one another, at $\mathbf{p}<0.001$ for BMT-NV-GEL

Values were significantly different from one another, at $\mathbf{p}<0.001$ for BMT-SOL

Zero time values for BMT-NV-GEL; TDC $(\%)=90.5 \pm 018$; Particle size $(\mathrm{nm})=806 \pm 10.5$.

Zero time TDC for BMT-SOL $(\%)=99.7 \pm 0.52$ 
Table 4: Stability study at $37 \pm 2^{\circ} \mathrm{C}(\mathrm{n}=3)$

\begin{tabular}{|c|c|c|c|c|}
\hline \multicolumn{5}{|c|}{$\%$ Change in parameters with time } \\
\hline \multirow{2}{*}{$\begin{array}{c}\text { Time } \\
\text { (months) }\end{array}$} & TDC & $\begin{array}{c}\text { In-situ gelling } \\
\text { behavior at } 37^{\circ} \mathbf{C}\end{array}$ & Particle size & TDC \\
\cline { 2 - 5 } & $1.03 \pm 0.12$ & Maintained & $1.24 \pm 0.860$ & $1.5 \pm 0.51$ \\
\hline 1 & $3.92 \pm 0.18$ & Maintained & $1.92 \pm 1.05$ & $7.9 \pm 1.0$ \\
\hline 3 & & & & \\
\hline
\end{tabular}

The BMT-NV-GEL was stable upto 3 months at $37{ }^{\circ} \mathrm{C}$. Though the study can be taken as the accelerated stability data but $37{ }^{\circ} \mathrm{C}$ (instead of $40{ }^{\circ} \mathrm{C}$ ) was selected to confirm that the particle would maintain their integrity upon subconjunctival injection and the drug will be released slowly therein following dilution with body fluids.

\subsection{Autoclavability}

The developed BMT-NV and BMT-NV-GEL were found to be stable on autoclaving with no significant change $(\mathrm{p}<0.05)$ in TDC, entrapment efficiency (determined for BMT-NV) and particle size (Table 5). Sterilization is an important consideration in the case of ocular delivery. Terminal sterilization is especially required in present case as we propose a preservative free unit dose prefilled package and/or vial to avoid damage usually observed with preservative like BAK. The selected components P407 and carbopol 934P of in-situ gelling formula are thermostable, change their performance with temperature and hence are harmonious to steam sterilization [60, 61]. It is reported that carbomers are stable and may be heated at high temperatures of $104^{\circ} \mathrm{C}$ for up to 2 hours without affecting their thickening efficiency. With an increase in temperature, many nonionic surfactants like tween $80\left(65^{\circ} \mathrm{C}\right.$, cloud point) become less hydrophilic [62]. An aqueous solution of these surfactants separates into two phases and becomes turbid at a certain temperature, which defines their cloud point. Dehydration of the emulsifier at temperatures above the cloud point may lead to a breakdown of the film around the oil droplets and consequently cause coalescence and destruction of the droplets [63]. Hence, the surfactant cloud point is an important consideration to determine the dispersion stability upon heat treatment (autoclaving). For example, using a surfactant with a comparatively high cloud point improved 
the emulsion's stability upon autoclaving viz. P407 (above $140^{\circ} \mathrm{C}$ ), and PEG400 (above $100{ }^{\circ} \mathrm{C}$ ) [63] employed presently. Resistance to change upon autoclaving observed presently is thus attributed to the presence of PEG400 as an outer layer (can be seen in TEM picture) around the vesicles. PEG being a plasticizer, increases the rigidity of the system facilitating stability to autoclaving and resist gelation [64]. At temperatures above the gelation the micelles change their shape from spheres to prolates, thereby negating their ability to assemble in a cubic packing. This leads to the reformation of the low viscosity sol phase. Above the cloud point $\left(>140^{\circ} \mathrm{C}\right)$, the micelles separate into their own coacervate phase in excess water. Since the autoclaving temperature is $121^{\circ} \mathrm{C}$ so latter is neither expected and was nor observed.

Table 5: Parameters before and after autoclaving $(n=3)$

\begin{tabular}{|c|c|c|c|c|c|c|}
\hline & \multicolumn{3}{|c|}{ BMT-NV } & \multicolumn{2}{|c|}{ BMT-NV-GEL-IM } & BMT-SOL $^{*}$ \\
\hline Autoclaving & $\% \mathrm{TDC}$ & EE (\%) & $\begin{array}{l}\text { Particle } \\
\operatorname{size}(n m) \\
\text { (PDI) }\end{array}$ & $\%$ TDC & $\begin{array}{l}\text { Particle size } \\
(\mathbf{n m}) \\
\text { ( PDI) }\end{array}$ & $\% \mathrm{TDC}$ \\
\hline Before & $91.65 \pm 1.21$ & $76.17 \pm 0.64$ & $\begin{array}{l}160.9 \pm 5.47 \\
(0.142 \pm 0.02)\end{array}$ & $90.23 \pm 1.15$ & $\begin{array}{l}820.9 \pm 7.12 \\
(0.312 \pm 0.05)\end{array}$ & $99.7 \pm 0.21$ \\
\hline After & $90.95 \pm 1.93$ & $75.27 \pm 1.57$ & $\begin{array}{l}169.8 \pm 8.19 \\
(0.140 \pm 0.03)\end{array}$ & $89.97 \pm 1.25$ & $\begin{array}{l}824.8 \pm 6.19 \\
(0.322 \pm 0.04)\end{array}$ & $93.95 \pm 1.91$ \\
\hline
\end{tabular}

*Values before and after autoclaving were not significantly different from one another within the group at p $<0.05$ except BMT-SOL.

\subsection{Sterility testing}

The developed and autoclaved blank formulation did not show growth of fungus and bacteria till 14 days and were found to be sterile. The positive control and validation test showed growth, confirming the suitability of media and absence of any inhibitory activity of the formulation. 


\subsection{Establishing the safety of the developed system is discussed under data in brief}

\subsection{Pharmacodynamic evaluation}

The baseline IOP was $15.26 \pm 1.3 \mathrm{mmHg}$ for all animals used in the study and there was no significant difference between all the 7 groups $(P=0.05 ; n=42)$. After induction of glaucoma the average IOP in animals of Gp II-V increased to $42.95 \pm 1.96$ which was maintained in Gp II animals throughout the study period. A significantly higher mean reduction of IOP following single subconjunctival BMT-NV-GEL-IM (Gp V)) administration compared to daily instillation of topical marketed lumigan eye drop (Gp IV) was observed upto 30 days. Results for BMT-NVGEL-IM group were comparable to marketed drop group from $30-34^{\text {th }}$ day. Beyond $34^{\text {th }}$ day IOP reduction in $\mathrm{GpV}$ was lower $(\mathrm{P}=0.05)$ than $\mathrm{Gp}$ IV but reduction was significant $(\mathrm{P}=0.05)$ with respect to the positive control (Gp III) animals (Fig. 6). Plateau phase observed from 36 to $40^{\text {th }}$ days indicates that the sustained action of BMT-NV-GEL-IM may extend even up to 2 months following single administration.

Ideally a treatment for glaucoma should maintain therapeutic level for long periods following single application [65]. Novel drug delivery strategies can achieve this by controlled release that sustains drug levels at the target site. Some inserts of antiglaucoma medicine for such extended release are already in market. DuraSite ${ }^{\circledR}$ system containing BMT showed ocular bioavailability superior to the conventional eye drops. However these (AzaSite and Besivance) need to be administered daily [66]. Similarly a chitosan-based ocular insert for BMT is also reported, which showed an effectiveness for over a month following sub-conjunctival application [67]. NOVADUR polymeric system for the sustained release of BMT is also reported [68]. The implant displayed IOP lowering efficiency for about six months however in this study $0.03 \%$ BMT drops were administered in contralateral eye daily. This may help in maintaining IOP of fellow eye [69].

Further the polymer used in the latter case is 250-300 times costlier than presently used components. Moreover a special applicator is recommended with this system. Intracameral administration of solid (polymeric) implant may also result in blurring of vision and irritation which is not expected with the presently developed in-situ gelling (semisolid viscous gel following administration) system of bimatoprost and its subconjunctival administration.

Subconjunctival injection is a promising method for delivery of controlled release medications. The subconjunctiva is a potential space that underlies the epithelial and connective tissue layers 
covering the sclera. Hence, it places the drug close to the external sclera. Further BMT has been reported to reduce IOP more profoundly by uveoscleral outflow pathway compared to trabecular meshwork outflow [9]. Hence subconjunctival administration of bimatoprost will result in better efficacy (injection closer to target site i.e. uveoscleral) and safety.

We also considered topical administration of BMT-NV-GEL formulation as an in situ gelling system, and compared the obtained results with the daily administration of Lumigan $0.03 \%$ drops. A significantly higher reduction in IOP, extending for three days following single drop administration, was achieved in comparison to the daily administration of Lumigan $0.03 \%$ drops. Furthermore, statistically significant reduction in IOP was noted for about one week in comparison to positive control group. This extended duration of action can thus enhance patient compliance and improve treatment outcomes. The enhanced effect and duration may be due to mucopenetrating action of poloxamer as well as mucoadhesive effect of Carbopol 934P. The NV system itself also has the capacity to release therapeutic entity for up to one week as also observed in the in-vitro release study (Fig. 5). 


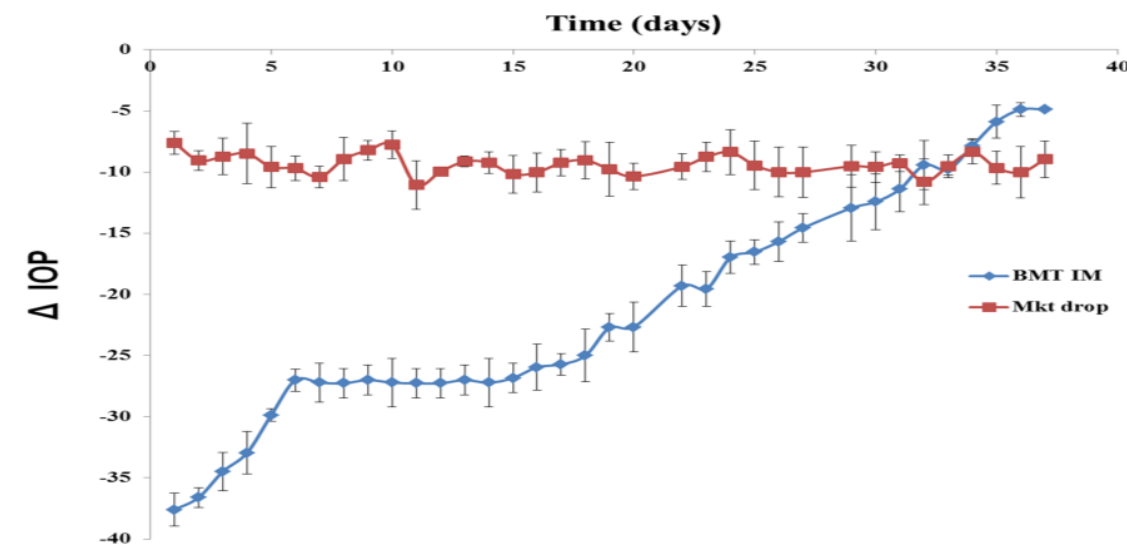

(a)

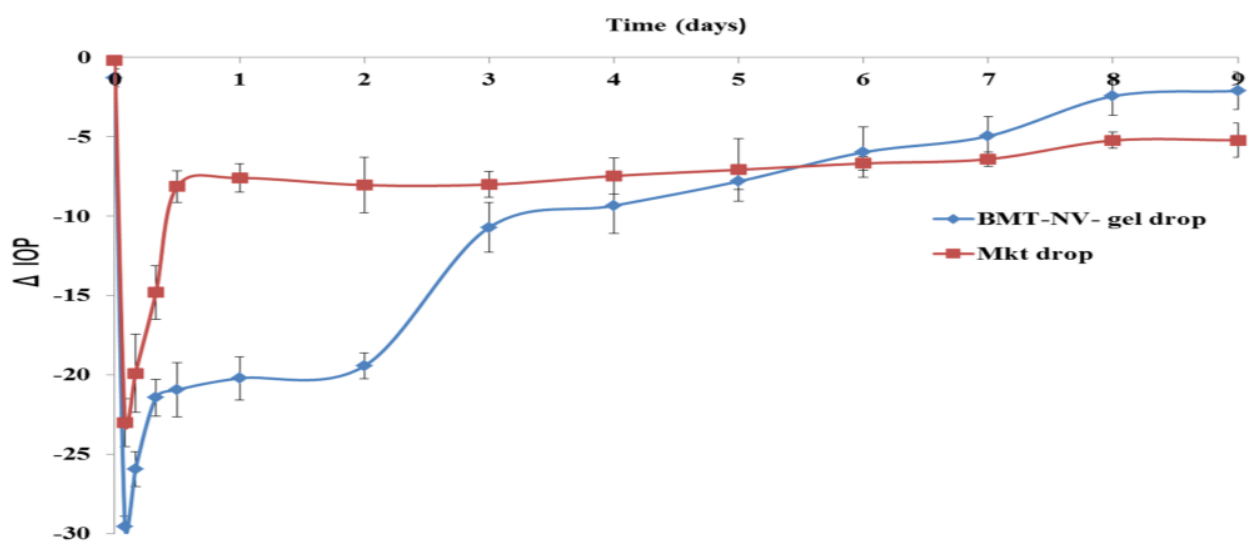

(b)

Fig.6: In vivo IOP reduction recording of single subconjunctival injection (100 $\mu \mathrm{l})($ a) and single drop administration $(30 \mu \mathrm{l})$ into the eye (b) of BMT-NV-GEL and its comparison with marketed (MKT) drops (Lumigan $0.03 \%$ ) administered daily.

\subsection{Proof of concept}

\subsubsection{Cellular uptake study}

Internalization of NV-GEL system was quantified by fluorometry. Significantly higher fluorescence was observed for F-GEL with respect to F-SOL in both type of cells i.e HCLE and HCjE (26-fold and 27-fold relative to F-SOL, respectively) (Fig.7) establishing superiority of the developed system. 

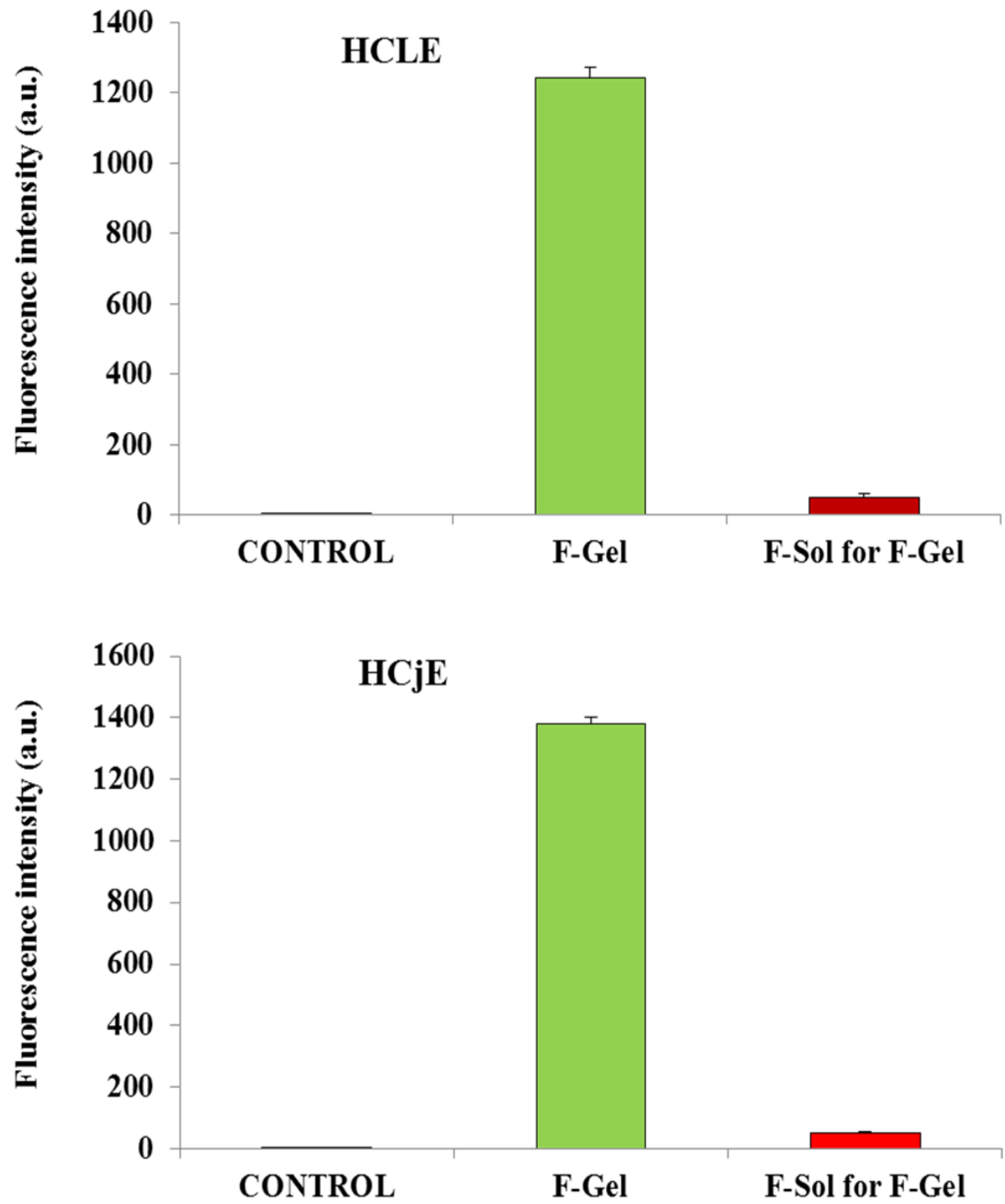

Fig. 7: Fluorescence intensity in HCLE and HCjE cells after incubation for $3 \mathrm{~h}$. Both values are significantly different from each other and with respect to control $(p<0.05)$.

A representative illustration of confocal microscopy, substantiates capacity of rat eye to retain the developed system even after 2 months of application following subconjunctival injection (Fig.8a). Similarly significant diffuse fluorescence in the whole eye even after one week following topical administration gives a direct evidence of sustained effect [70] of the developed system (Fig.8b). 

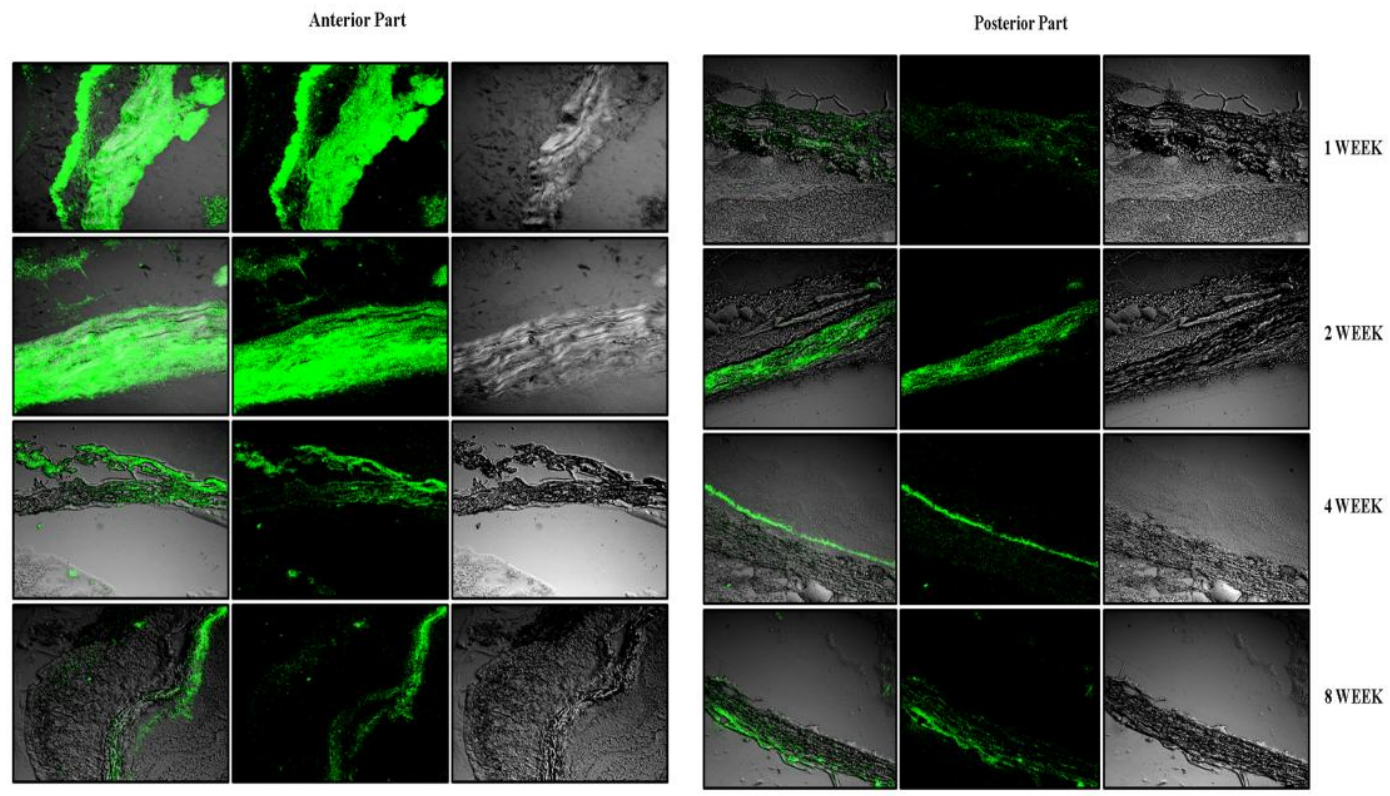

(a)

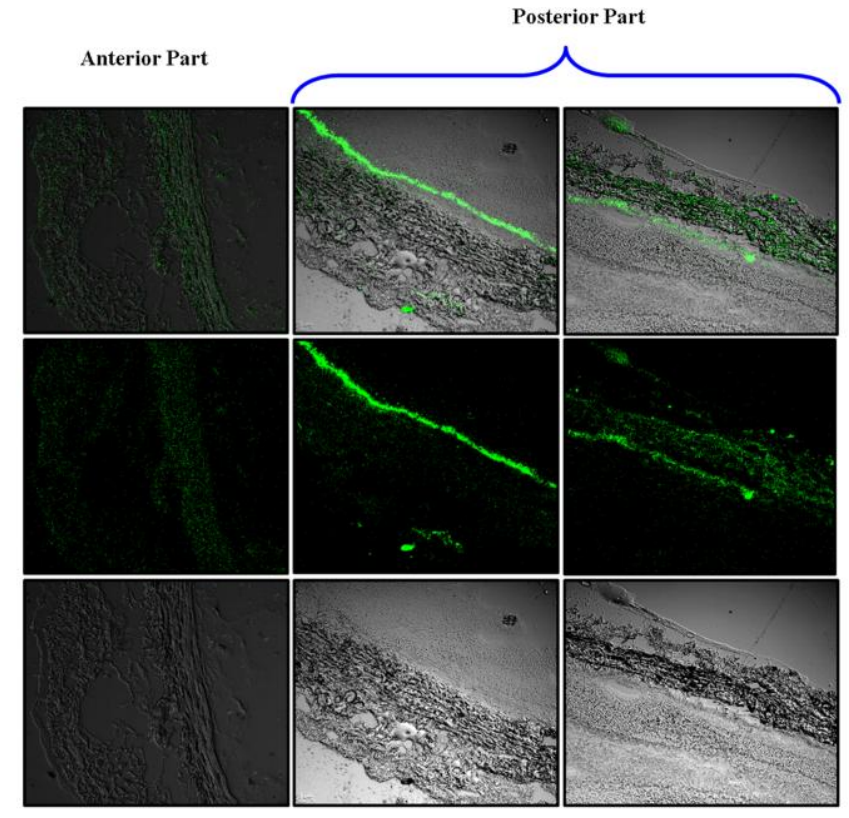

(b)

Fig.8: Confocal images at different time points of BMT-NV-GEL subconjunctival injection (a) and after topical application $(b)$. 


\section{CONCLUSIONS}

Glaucoma is a chronic ocular disease requiring lifelong medication once initiated. Daily once or twice administration of drops results in poor patient compliance especially in elderly persons above 60 years of age. Presently BMT nanovesicles loaded poloxamer based in-situ gelling implant was successfully produced.

A successful incorporation of BMT-NV into gel was confirmed by DSC and FTIR spectra. Further a strong intertwines interaction between the P407 and Carbopol 934P was achieved and confirmed by FTIR spectra. The sustained release of BMT was proven by pharmacodynamic effects (IOP lowering) and in vitro release studies. Developed implant was able to sustain the release of BMT over 2 month with single subconjunctival injection. Furthermore single administration as topical drop effectively lowered the IOP for 7 days. These results may reveal a potential application of this new formulation in glaucoma management, in order to improve patient compliance by lowering the frequency of administration and enhancing the therapeutic effectiveness of glaucoma medical treatment.

\section{CONFLICT OF INTEREST}

The authors report no conflict of interest. 


\section{6. $\quad$ References}

[1] Y.C. Tham, X. Li, T.Y. Wong, H.A. Quigley, T. Aung, C.Y. Cheng, Ophthalmology, 121 (2014) 20812090.

[2] V.A. Guerrero, M. Zongc, E. Ramsay, B. Rojas, S. Sarkhel, B. Gallego, R. Hoz, A.I. Ramírez, J.J. Salazar, A. Trivino, J.M. Ramírez, E.M. Amo, N. Camerong, B.D. Heras, A. Urtti, G. Mihov, A. Dias, R.H. Vanrell, J. Control. Release, 211 (2015) 105-117.

[3] X.W. Ng, K.L. Liu, A.B. Veluchamy, N.C. Lwin, T.T. Wong, S.S. Venkatraman, Drug Deliv Transl Res, (2015) DOI 10.1007/s13346-13015-10240-13344.

[4] J.M. Michael, C.L. Samuel, A.S. Jeanette, C.S. William, Clin. Ophthalmol., 4 (2010) 1355-1359.

[5] T.V. Johnson, P.K. Gupta, D.K. Vudathala, L.A. Blair, A.P. Tanna, J Ocular Pharm Ther

27 (2011).

[6] D.F. Woodward, A.H.P. Krauss, J.C.Y. Liang, C. LI, C.E. Protzman, JPET, 305 (2003) 772-785.

[7] J.G. Walt, J.T. Lee, Surv. Opthamol., 49 (2004) 2004.

[8] K. Wang, L. Xu, Z. Yuan, K. Yao, J. Zhao, L. Xu, A. Fang, M. Zhang, L. Wu, J. Ji, J. Hou, Q. Liu, X. Sun, BMC Ophthalmol., 14 (2014) 1-15.

[9] M. Figus, M. Nardi, P. Piaggi, M. Sartini, G. Guidi, L. Martini, S. Lazzeri, Eye, 28 (2014) 422-429.

[10] J.M. Michael, C.L. Samuel, A.S. Jeanette, C.S. William, Clin. Ophthalmol. , 4 (2010) 1355-1359.

[11] G. Reardon, S. Kotak, G.F. Schwartz Patient Prefer. Adherence, 5 (2011) 441-463.

[12] J.H. Gurwitz, R.J. Glynn, M. Monane, D.E. Everitt, D. Gilden, N. Smith, J.T. Avorn, Am J Public Health, 83 (1993) 711-716.

[13] B.L. Nordstrom, D.S. Friedman, E. Mozaffari, H.A. Quigley, A.M. Walker, Am. J. Ophthalmol., 140 (2005) 598-596.

[14] D.T.L. Quek, G.T. Ong, S.A. Perera, E.L. Lamoureux, T. Aung, Arch. Ophthalmol., 129 (2011) 643-648.

[15] M.M. Brown, G.C. Brown, G.L. Spaeth, Can. J. Ophthalmol., 19 (1984) 2-5.

[16] X. Yang, H.M. Trinh, V. Agrahari, Y. Sheng, D. Pal, A.K. Mitra, AAPS, 17 (2016) 294-306.

[17] J.V. Natarajan, M. Ang, A. Darwitan, S. Chattopadhyay, T.T. Wong, S.S. Venkatraman, Int J Nanomedicine, 7 (2012) 123-131.

[18] H.J. Jung, A. Chauhan, J Ocul Pharmacol Ther, 29 (2013) 229-235.

[19] E. Schaefer, S.M. Smith, J. Salmon, S. Abbaraju, R. Amin, S. Weiss, U. Grau, P. Velagaleti, B. Gilger, J. Ocul. Pharmacol. Ther., 33 (2017) 353-360.

[20] L. Zhang, W. Shen, J. Luan, D. Yang, G. Wei, L. Yu, W. Lu, J. Ding, Acta Biomater., 23 (2015) 271-281.

[21] L. Xi, T. Wang, F. Zhao, Q. Zheng, X. Li, PLOS ONE, 9 (2014) e100632.

[22] E. Lavik, M.H. Kuehn, A.J. Shoffstall, K. Atkins, A.V. Dumitrescu, Y.H. Kwon, J. Ocu.I Pharmacol. Ther., 32 (2016) DOI: 10.1089/jop.2016.0042.

[23] H. Nascimento, M. Franca, L.G. García, C. Muccioli, R. Belfort, J. Ophthalmic. Inflamm. Infect., 3 (2013) doi:10.1186/1869-5760.

[24] F. Zahir-Jouzdani, J.D. Wolf, F. Atyabi, A. Bernkop-Schnürch, Expert Opin Drug Deliv., 15 (2018) 1007-1019.

[25] P. Sánchez, J.L. Pedraz, G. Orive, Int. J. Biol. Macromol. , 98 (2017) 486-494.

[26] M. Ang, X. Ng, C. Wong, P. Yan, S.P. Chee, PLOS ONE, 9 (2014) e97555.

[27] A.A. Zaki, S.F. Farid, Acta Ophthalmologica, 88 (2010) 868-871.

[28] X. Jiang, L. Huibin, Q. Weiqiang, Z. Liu, X. Li, W. Wang, Drug Des. Dev. Ther., 9 (2015) 3043-3050.

[29] J.R. Franca, G. Foureaux, L.L. Fuscaldi, T.G. Ribeiro, L.B. Rodrigues, R. Bravo, R.O. Castilho, M.I. Yoshida, N. Cardoso, S.O. Fernandes, S. Cronemberger, A.J. Ferreira, A.A.G. Faraco, PLOS ONE, 9 (2014) 95461.

[30] P. Balakrishnan, E.K. Park, C.K. Song, H.J. Ko, T.W. Hahn, K.W. Song, H.J. Cho, Molecules, 20 (2015) 4124-4135. 
[31] IP, The Indian Pharmacopoeia Commission, Ghaziabad, India, 1 (2007) 52-59.

[32] M. Yadav, A. Guzman-Aranguez, M.J. Perez de Lara, M. Singh, J. Singh, I.P. Kaur, Mater. Sci. Eng. C. In Press., (2019).

[33] N. Razali, R. Agarwal, P. Agarwal, M.Y. Kapitonova, M.K. Kutty, A. Smirnov, N.S. Bakar, N.M. Ismail, Eur. J. Pharmacol., 749 (2015) 73-80.

[34] D.R. Overby, A.F. Clark, Exp. Eye. Res., 141 (2015) 22.

[35] A.P. Wells, J.G. Crowston, J. Marks, J.F. Kirwan, G. Smith, J.C.K. Clarke, R. Shah, J. Vieira, C. Bunce, I. Murdoch, P.T. Khaw, J Glaucoma, 13 (2004) 454-460.

[36] J. Joby, T.H. Józef, T. Sabu, G. Sreeraj, Material Today Chemistry, 9 (2018) 43-55.

[37] H. Almeida, M.H. Amaral, P. Lobão, J.M. Lobo, Drug Discov Today., 19 (2014) 400-412.

[38] F. Zahir-Jouzdani, J.D. Wolf, F. Atyabi, A. Bernkop-Schnürch, Expert Opin Drug Deliv. , 15 (2018) 1007-1019.

[39] A.H. El-Kamel, Int J Pharm, 241 (2002) 47-55.

[40] M. Mansour, S. Mansour, N.D. Mortada, S.S. Abd Elhady, Drug Dev. Ind. Pharm., 34 (2008) 744-752.

[41] F. Artzner, S. Geiger, A. Olivier, C. Allais, S. Finet, F. Agnely, Langmuir, 23 (2007) 5085-5092.

[42] L. Klouda, A.G. Mikos, Eur. J. Pharm. Biopharm., 68 (2008) 34-45.

[43] J. Chen, R. Zhou, L. Li, B. Li, X. Zhang, J. Su, Molecules, 18 (2013) 12415-12425.

[44] Q. Hongyi, C. Wenwen, H. Chunyan, L. Li, C. Chuming, W. Li, W. Chunjie, Int. J. Pharm., 337 (2007) 178-187.

[45] A.H.H. Talasaz, A.A. Ghahremankhani, S.H. Moghadam, R.M. Mazda, F. Atyabi, R. Dinarvand, J Appl Polym Sci, 109 (2008) 2369-2374.

[46] T. Gratieri, G.M. Gelfuso, E.M. Rocha, V.H. Sarmento, O. Freitas, R. Fonseca, V. Lopez, Eur. J. Pharm. Biopharm., 75 (2010) 186-193.

[47] E. Schnitzer, I. Pinchuk, A. Bor, A. Leikin-Frenkel, D. Lichtenberg, Chem. Phys. Lipids., 146 (2007) 4353.

[48] A. Wagner, K. Vorauer-Uhl, J. Drug Deliv., 9 (2011) 591325.

[49] I.P. Kaur, V. Kakkar, P.K. Deol, M. Yadav, M. Singh, I. Sharma, J. Control. Release, 193 (2014) 51-62.

[50] I.Q.C. FDA,

https://www.fda.gov/Drugs/GuidanceComplianceRegulatoryInformation/Guidances/ucm125820.htm, accessed 12-2-15).

[51] FDA, (https://www.accessdata.fda.gov/scripts/cder/iig/getiigWEB.cfm, acesssed 26.04.2017).

[52] D.A. Owens, N.A. Peppas, Int J Pharm, 307 (2006) 93-102.

[53] M.L. Immordino, F. Dosio, L. Cattel, Int. J. Nanomedicine, 1 (2006) 297-315.

[54] Q. Wang, T. Gong, X. Sun, Z. Zhang, Colloids. Surf. B, 84 (2011) 406-412.

[55] A.C. Amrite, U.B. Kompella, J Pharm Pharmacol, 57 (2005) 1555-1563.

[56] A.C. Amrite, H.F. Edelhauser, S.R. Singh, U.B. Kompella, Mol. Vis., 14 (2008) 150-160.

[57] N. Pawar, H.B. Bohidar, Colloids. Surf. A., 333 (2009) 120-125.

[58] F. Cao, X. Zhang, Q. Ping, Drug Deliv., 17 (2010) 500-507.

[59] R. Bhandari, I.P. Kaur, Int. J. Pharm., 441 (2013) 202-212.

[60] R. Cavalli, O. Caputo, C.M. Eugenia, M. Trotta, C. Scarnecchia, M.R. Gasco, Int. J. Pharm., 148 (1997) 47-54.

[61] K. Goke, E. Roese, A. Arnold, J. Kuntsche, H. Bunjes, Mol. Pharm., 13 (2016) 3187-3195.

[62] A.V. Kabanov, I.R. Nazarova, I.V. Astafieva, E.V. Batrakova, V.Y. Alakhov, A.A. Yaroslavov, V.A. Kabanov, Macromolecules, 28 (1995) 2303-2314.

[63] M. Jumaa, B.W. Müller, Int. J. Pharm., 174 (1998) 29-37.

[64] K.E. Pramono, S.B. Utomo, V. Wulandari, A.W. Zahrotul, F. Clegg, J. Phys. Conf. Ser., 776 (2016) 012054. 
[65] P.K. Gupta, M. Aqil, K. R.K, A. Ali, A. Bhatnagar, G. Mittal, Nanomed. Nanotech. Biol. Med., 6 (2010) 324-333.

[66] A. Shafiee, L.M. Bowman, E. Hou, K. Hosseini, Clin. Ophthalmol. 7 (2013) 1549-1556.

[67] Y.K. Han, J.W. Kwon, J.S. Kim, C.S. Cho, W.R. Wee, J.H. Lee, Br. J. Ophthalmol., 87 (2003) 1399-1402.

[68] M.R. Robinson, J. Burke, R. Schiffman, Allergan Inc., (2011).

[69] A.M. Kalam, Y. Sultana, A. Ali, M. Aqil, A.K.C.K. Mishra, I.A. Aljuffali, A. Alshamsan, J. Appl. Polym. Sci., 101 (2013) 1828-1836.

[70] R. Gaudana, H.R. Ananthula, A. Parenky, A.K. Mitra, AAPS, 12 (2010) 348-360. 


\section{Graphical abstract}

\section{BMT-NV-GEL}

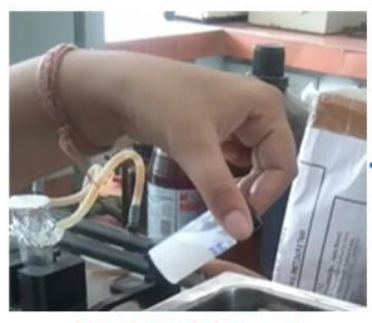

Liquid at or below room temperature
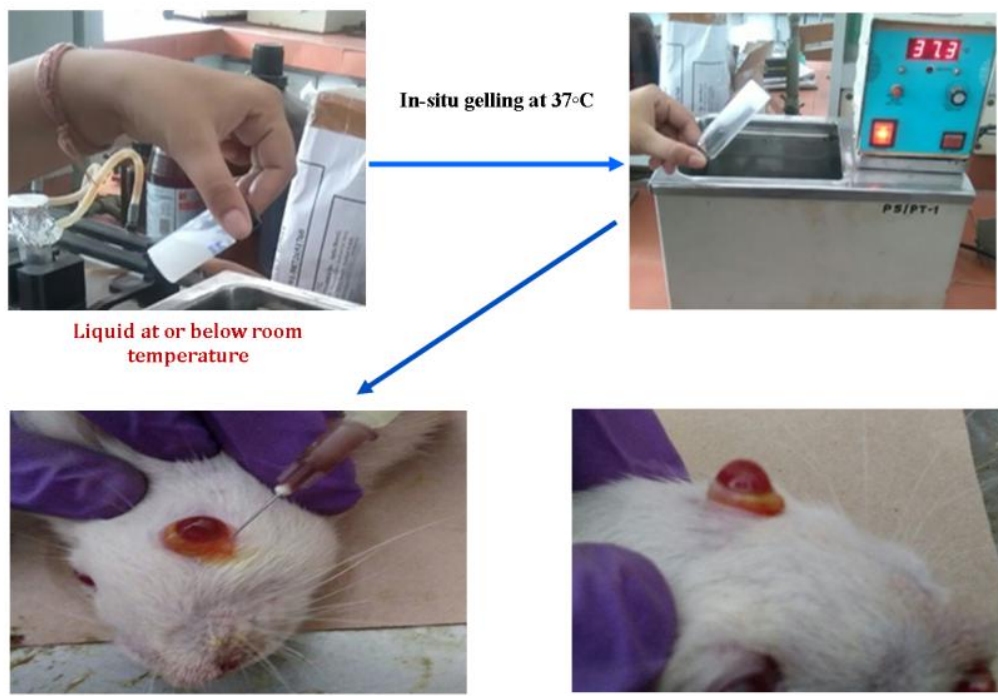

Subconjunctival Injection $\downarrow$

흠
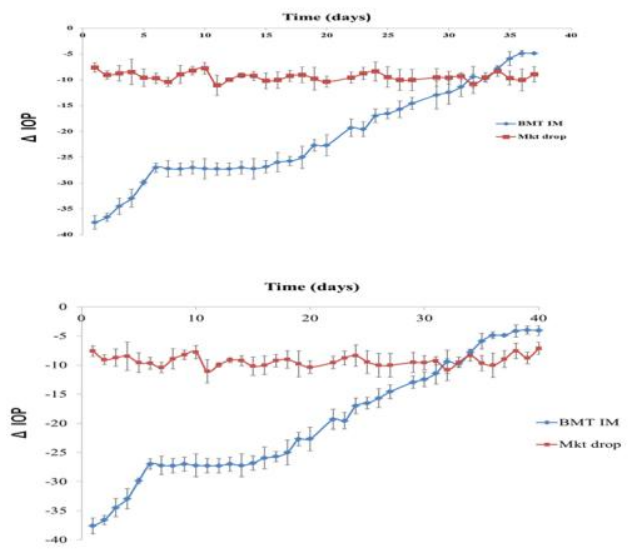

IOP Lowering effect

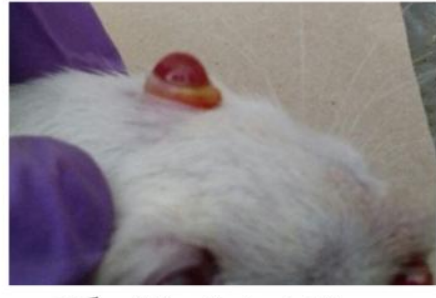

0 time after implantation

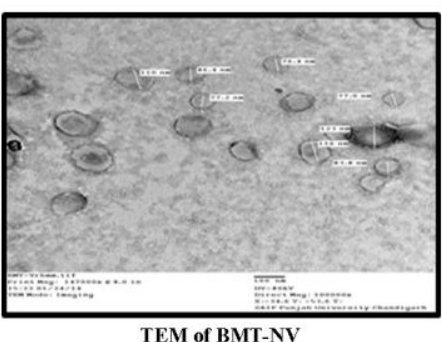

TEM of BMT-NV

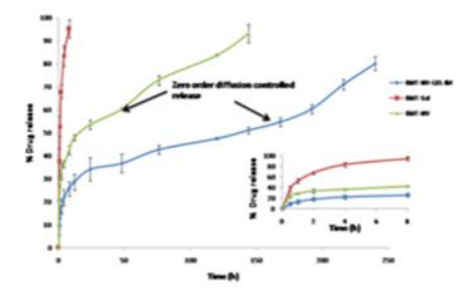

Invitro release studies
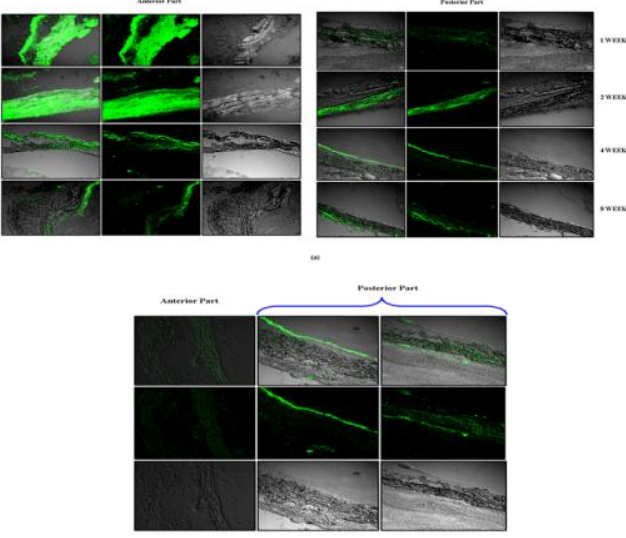

Proof of Concept 


\section{Highlights}

- Bimatoprost (BMT) is a pharmacologically superior prostamide, as it lowers intraocular pressure (IOP) by dual pathways.

- Presently BMT was encapsulated in a surfactant-based novel nanovesicular (NV) system with greater stability, low cost and ease of preparation vis a vis a liposomal system.

- TEM images of the BMT-NV indicate small size (165.7 $\pm 10.5 \mathrm{~nm}$; $\mathrm{n}=6$ ), round, unilamellar/bilamellar structures with no aggregation or irregularities and high encapsulation efficiency of $76.8 \pm 1.52 \%(n=6)$.

- BMT-NV were incorporated into in-situ gelling drops (GEL) or implant (GEL-IM) to achieve sustained effects from a single application.

- Sol-gel transition temperature of the final formulation was found to be $37 \pm 0.5^{\circ} \mathrm{C}(\mathrm{n}=6)$.

- BMT showed a prolonged release with 93\% drug release at $144 \mathrm{~h}$ (6 days) from BMTNV. BMT-NV-GEL showed an even better sustained effect with $51 \%$ drug release at 144 $\mathrm{h}$ and $80.23 \%$ at $240 \mathrm{~h}$ (10 days).

- Single injection of BMT-NV-GEL-IM group compared to daily application of marketed drops for more than a month.

- Developed formulation showed 26 to 27-fold improved permeation into corneal (HCLE) and conjunctival (HcjE) cells.

- Confocal microscopy substantiated capacity of rat eye to retain the developed system for more than 2 months following sub-conjunctival implantation. 


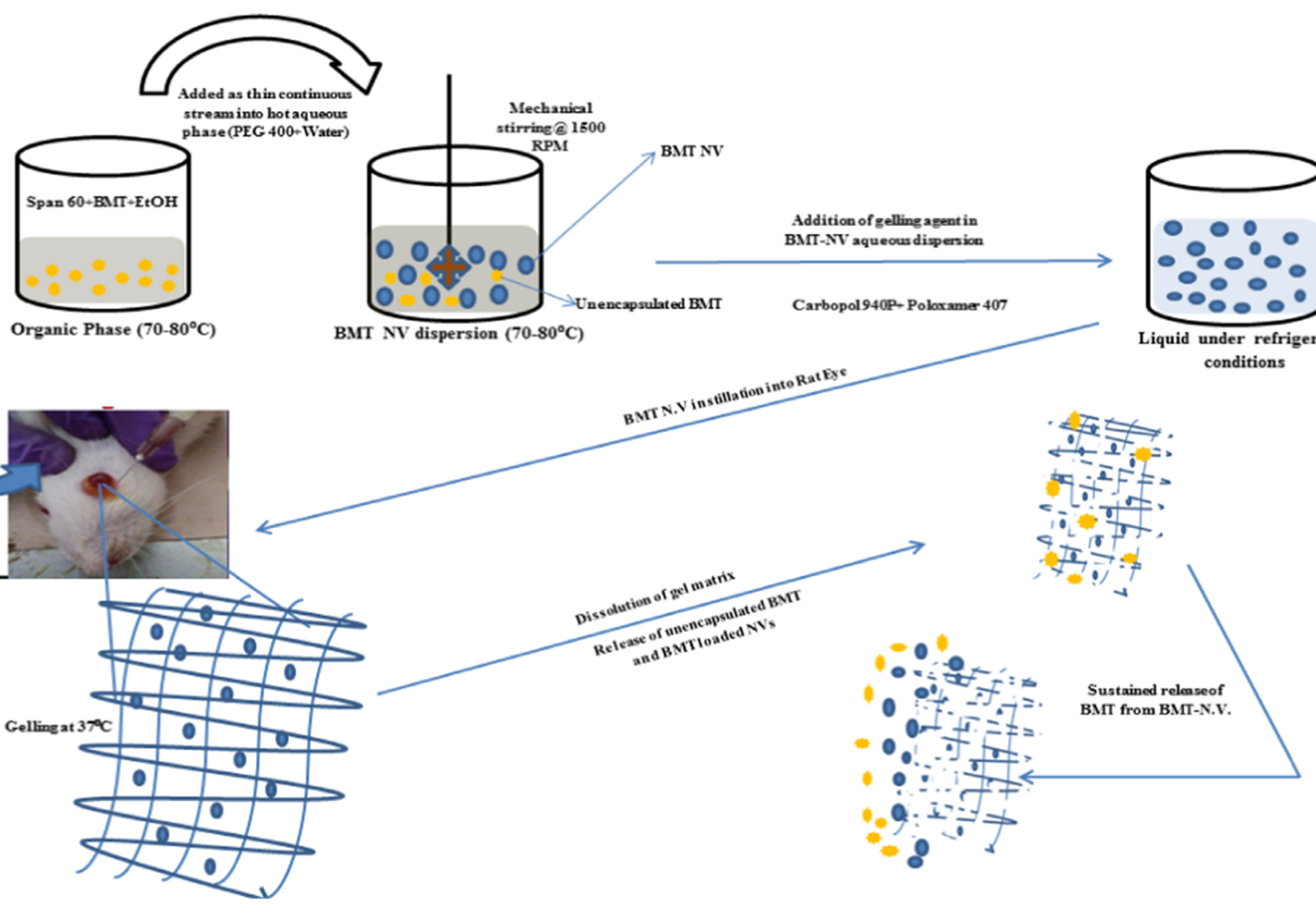

Figure 1 


\section{In vivo experimental design}

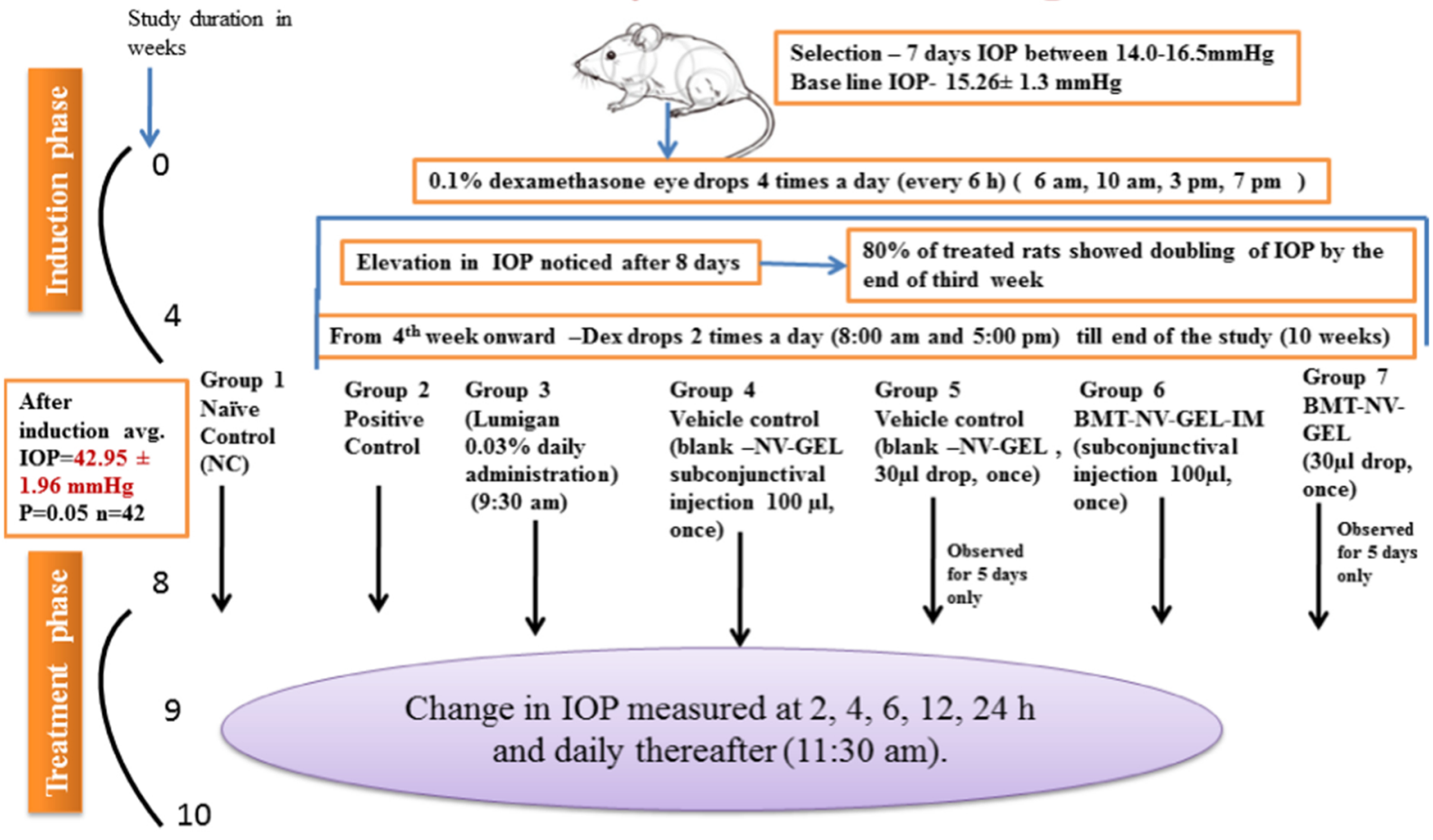




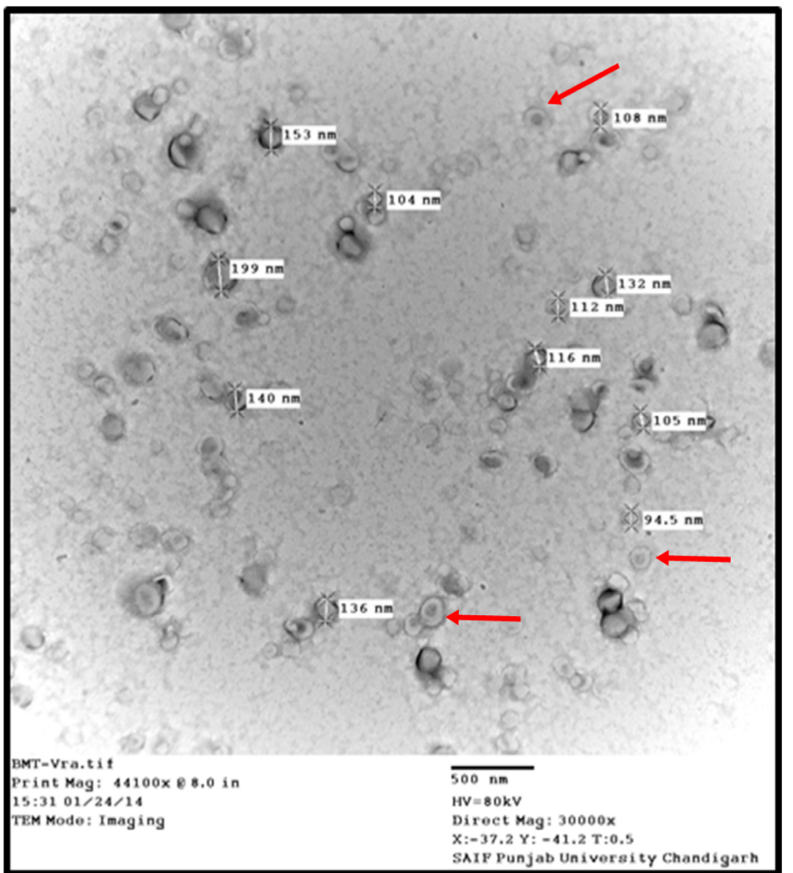

(a)

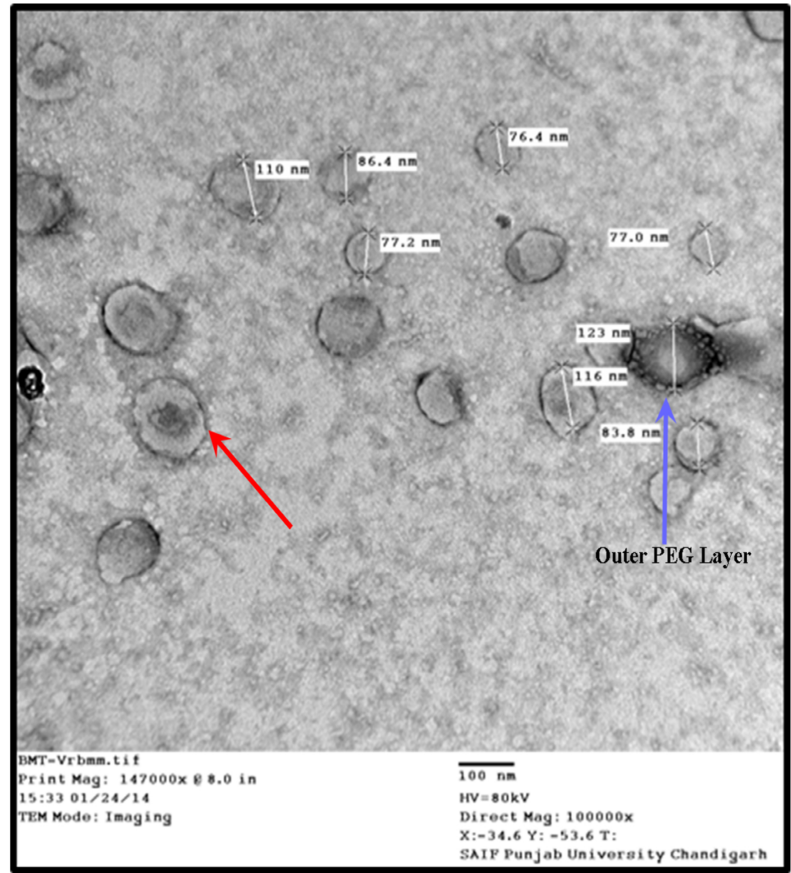

(b)

Figure 3 


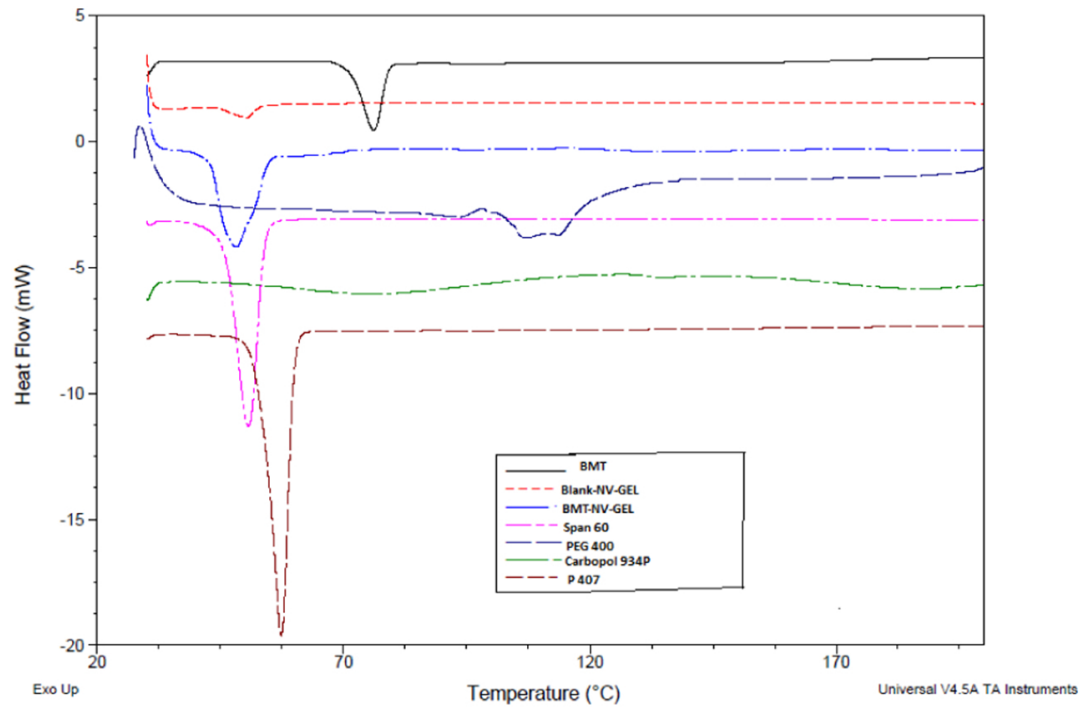

(a)

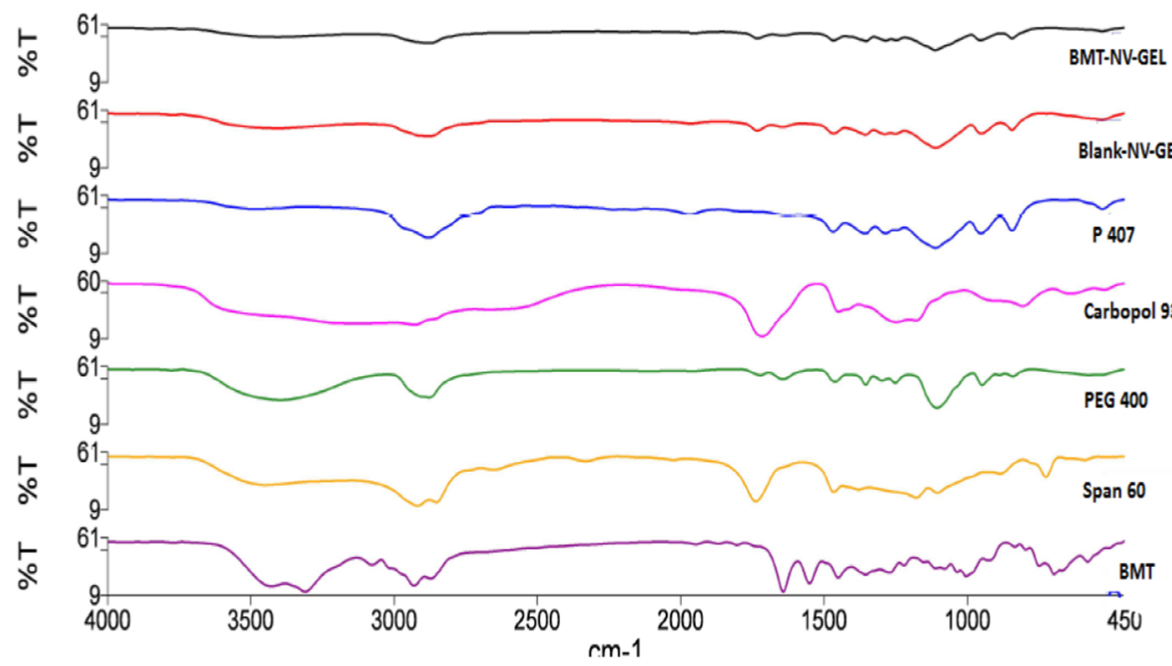

(b)

Figure 4 


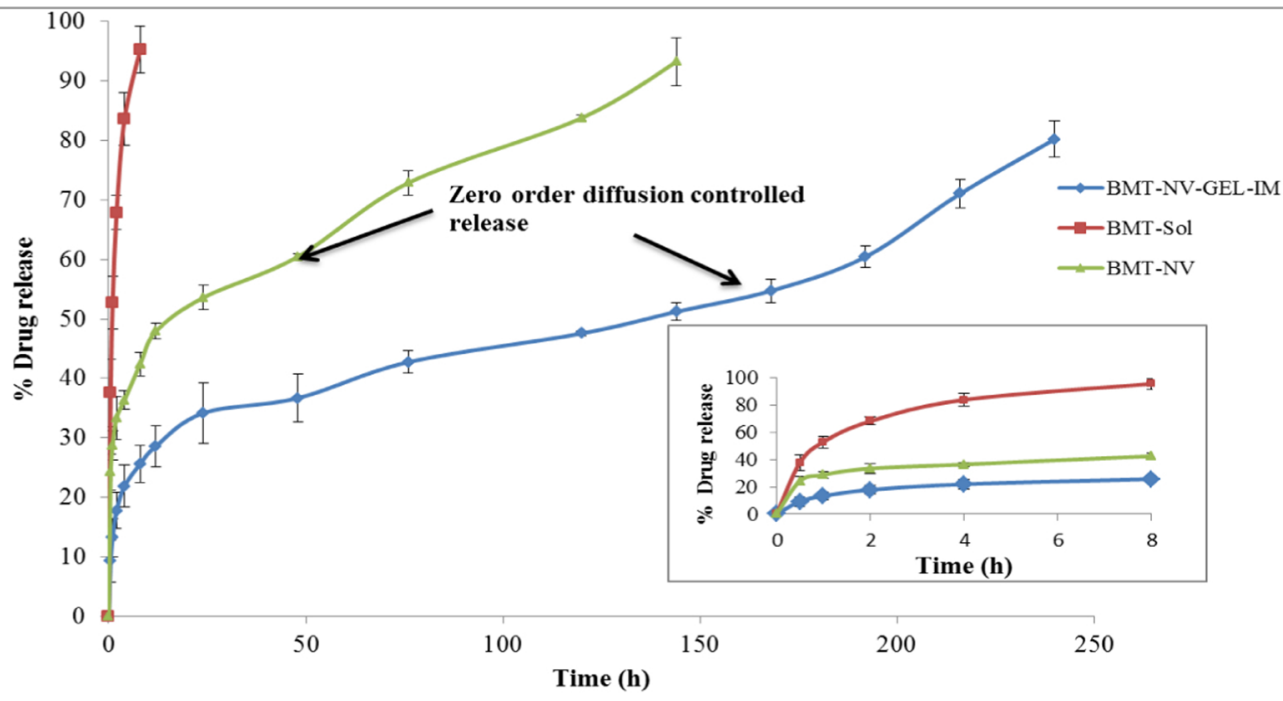

Figure 5 


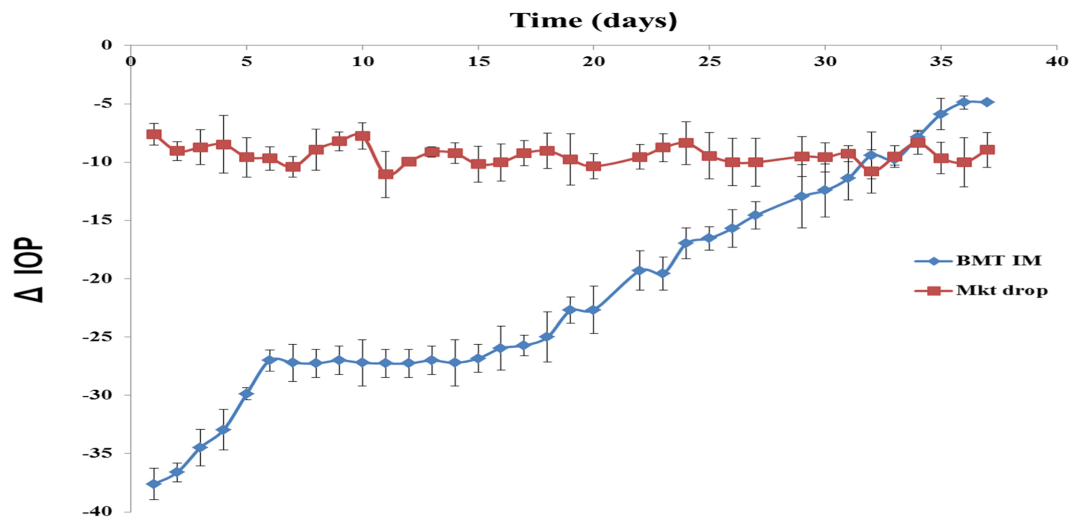

(a)

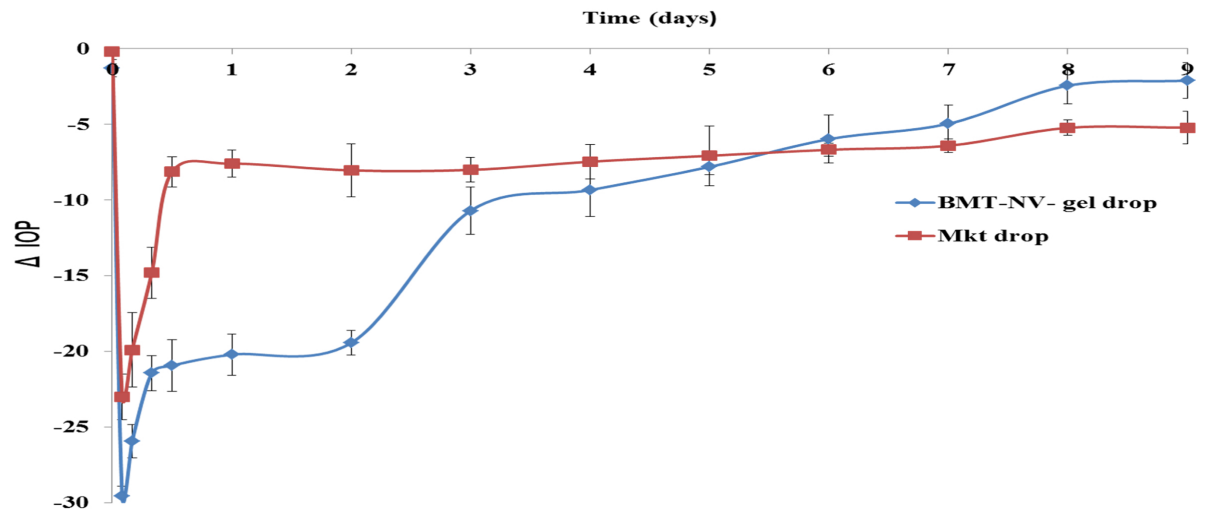

(b)

Figure 6 

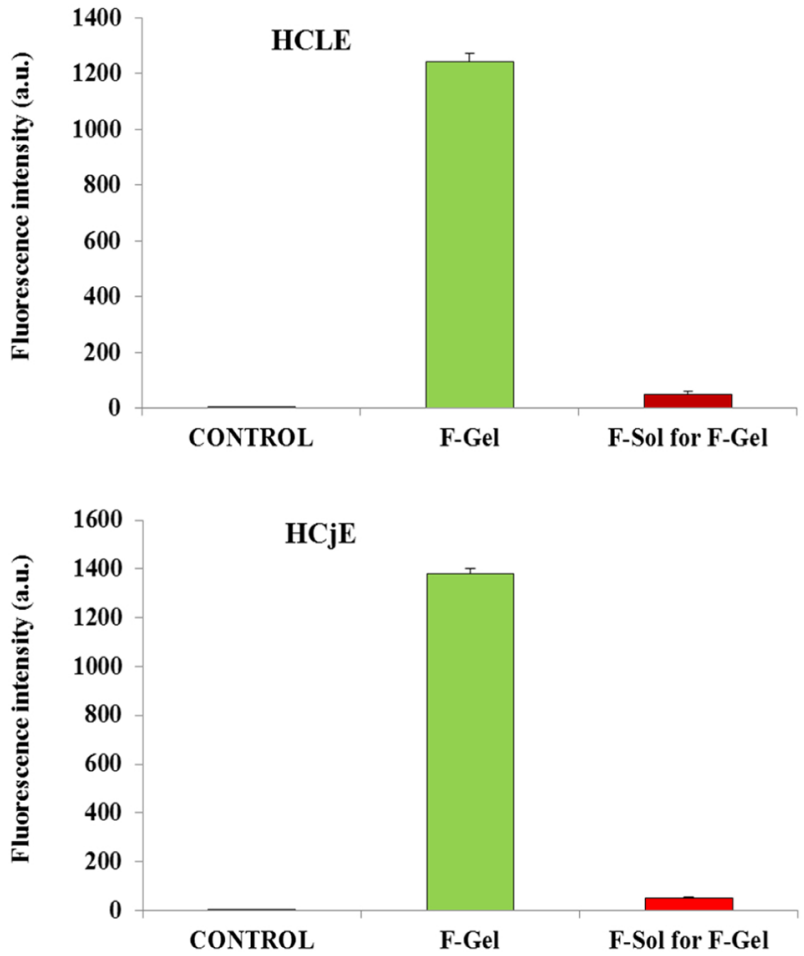

Figure 7 
Anterior Part

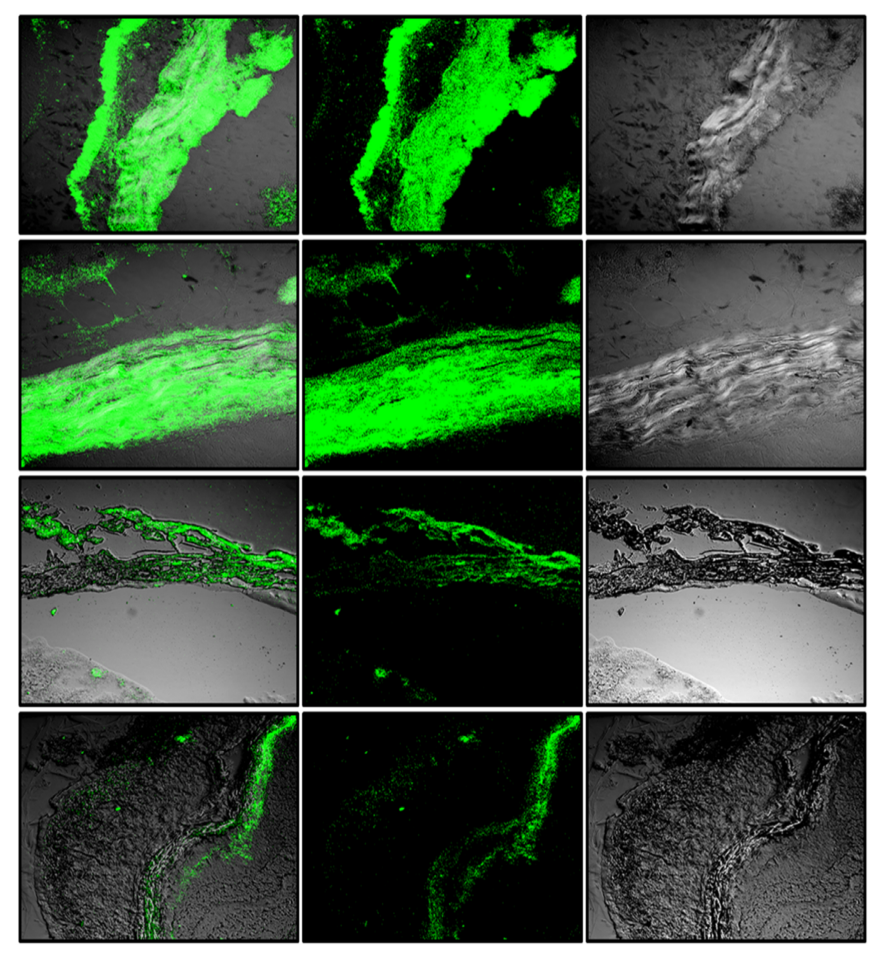

Posterior Part

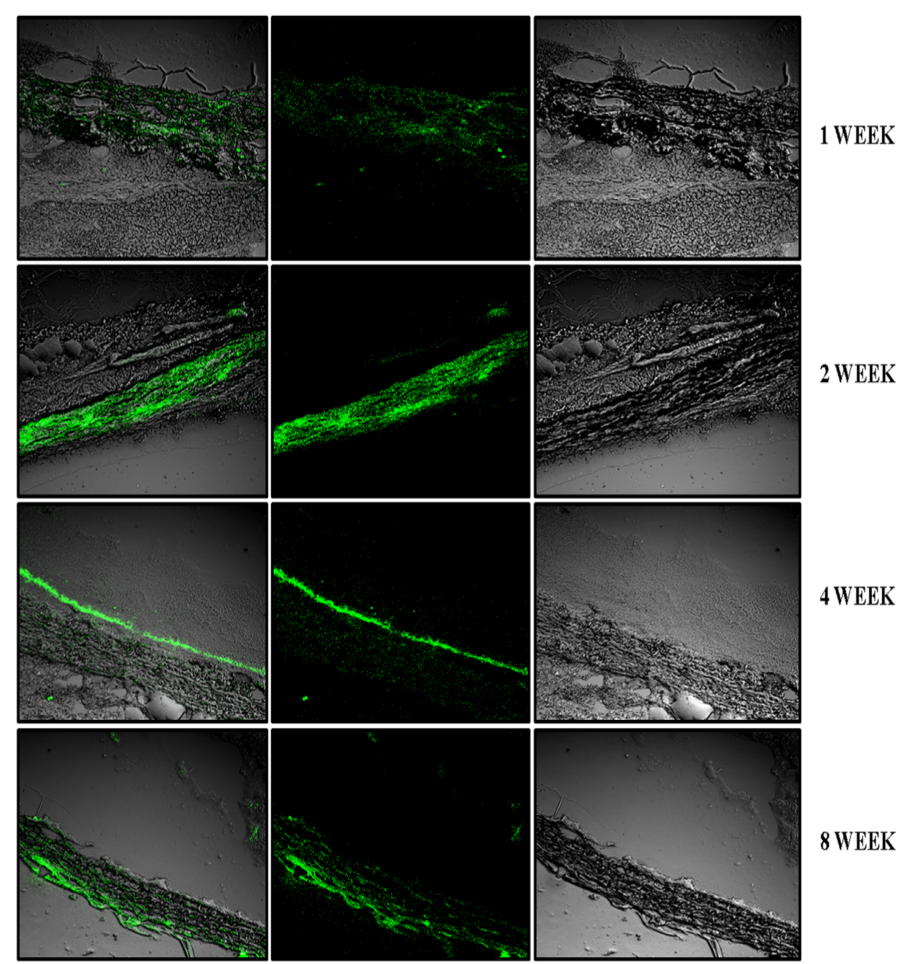

(a)

Posterior Part

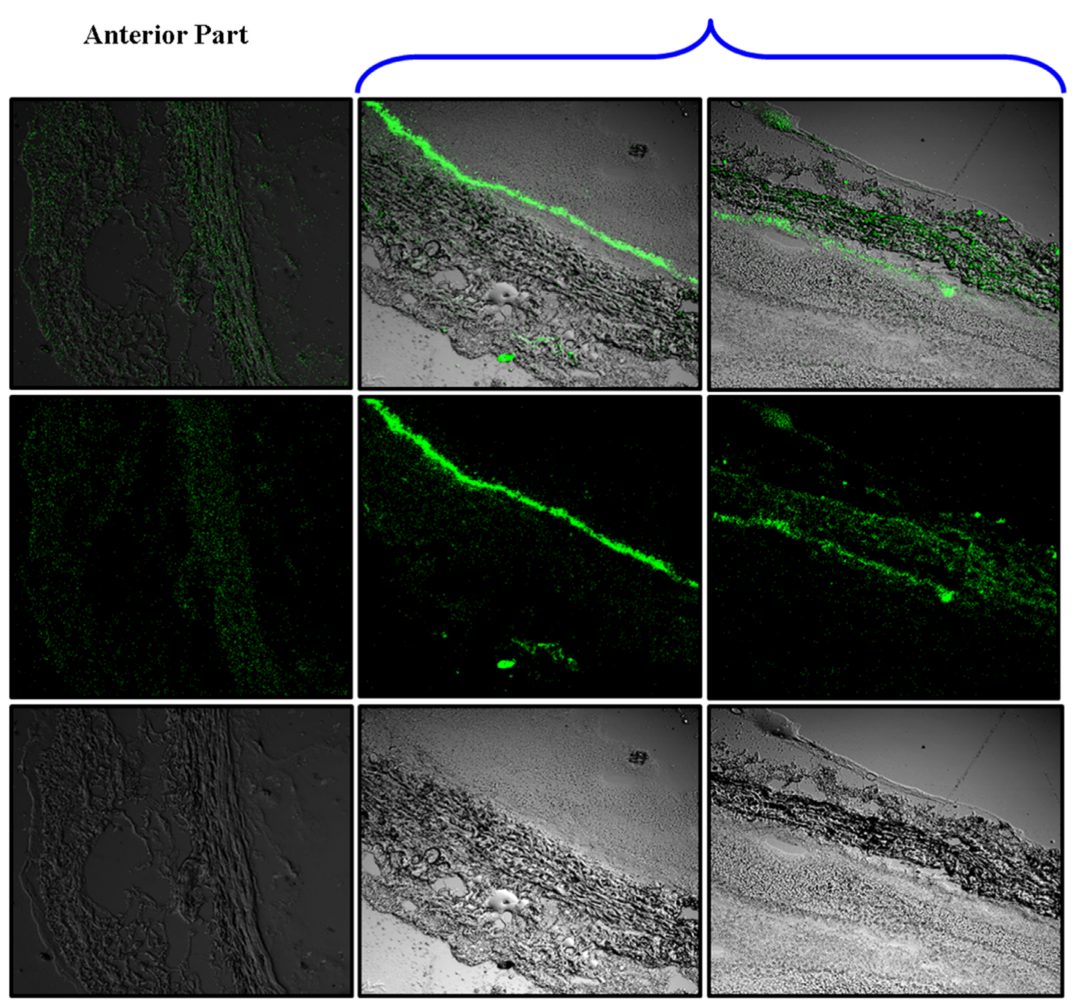

(b)

Figure 8 